\title{
Improving flood forecasting capability of physically based distributed hydrological models by parameter optimization
}

\author{
Y. Chen ${ }^{1}$, J. Li ${ }^{1}$, and H. Xu ${ }^{2}$ \\ ${ }^{1}$ Department of Water Resources and Environment, Sun Yat-sen University, Room 108, Building 572, \\ Guangzhou 510275, China \\ ${ }^{2}$ Bureau of Hydrology and Water Resources of Fujian Province. Fuzhou, Fujian, China \\ Correspondence to: Y. Chen (eescyb@mail.sysu.edu.cn)
}

Received: 1 October 2015 - Published in Hydrol. Earth Syst. Sci. Discuss.: 16 October 2015

Accepted: 5 January 2016 - Published: 21 January 2016

\begin{abstract}
Physically based distributed hydrological models (hereafter referred to as PBDHMs) divide the terrain of the whole catchment into a number of grid cells at fine resolution and assimilate different terrain data and precipitation to different cells. They are regarded to have the potential to improve the catchment hydrological process simulation and prediction capability. In the early stage, physically based distributed hydrological models are assumed to derive model parameters from the terrain properties directly, so there is no need to calibrate model parameters. However, unfortunately the uncertainties associated with this model derivation are very high, which impacted their application in flood forecasting, so parameter optimization may also be necessary. There are two main purposes for this study: the first is to propose a parameter optimization method for physically based distributed hydrological models in catchment flood forecasting by using particle swarm optimization (PSO) algorithm and to test its competence and to improve its performances; the second is to explore the possibility of improving physically based distributed hydrological model capability in catchment flood forecasting by parameter optimization. In this paper, based on the scalar concept, a general framework for parameter optimization of the PBDHMs for catchment flood forecasting is first proposed that could be used for all PBDHMs. Then, with the Liuxihe model as the study model, which is a physically based distributed hydrological model proposed for catchment flood forecasting, the improved PSO algorithm is developed for the parameter optimization of the Liuxihe model in catchment flood forecasting. The improvements include adoption of the linearly decreasing inertia weight strategy to change the inertia weight and the arccosine function
\end{abstract}

strategy to adjust the acceleration coefficients. This method has been tested in two catchments in southern China with different sizes, and the results show that the improved PSO algorithm could be used for the Liuxihe model parameter optimization effectively and could improve the model capability largely in catchment flood forecasting, thus proving that parameter optimization is necessary to improve the flood forecasting capability of physically based distributed hydrological models. It also has been found that the appropriate particle number and the maximum evolution number of PSO algorithm used for the Liuxihe model catchment flood forecasting are 20 and 30 respectively.

\section{Introduction}

Improving flood forecasting capability has long been the goal of the global hydrological community, and catchment hydrological models are the main tools for flood forecasting. The first model used for flood forecasting is commonly referred to as the Sherman's unit hydrograph method (Sherman, 1932). Early catchment hydrological models are usually referred to as lumped conceptual models (Refsgaard et al., 1996; Chen et al., 2011), and a large number of this kind of models have been proposed, such as the Stanford model (Crawford et al., 1966), the Xinanjiang model (Zhao, 1977), and many other lumped models included in the book Computer Models of Watershed Hydrology (Singh et al., 1995). Lumped conceptual models usually aggregate the hydrological forcings, state variables and model parameters over the whole catchment, so they could not represent the spatial distribution of 
the terrain characteristics and hydrological forcings finely, thus reducing their flood forecasting capabilities. With the development of remote sensing and GIS techniques, highresolution terrain data such as those from the Shuttle Radar Topography Mission digital elevation model (DEM) database (Falorni et al., 2005; Sharma et al., 2014), the USGS land use type database (Loveland et al., 1991, 2000), the FAO soil type database (http://www.isric.org), and precipitation estimated by digital weather radar (Fulton et al., 1998; Chen et al., 2009) have been prepared and freely available globally. This largely facilitated the development of physically based distributed hydrological models (PBDHMs). PBDHMs divide the terrain of the whole catchment into a number of grid cells at fine resolution and assimilate different terrain data and precipitation to different cells, thus having the potential to improve the catchment hydrological process simulation and prediction capability (Ambroise et al., 2006). A dozen of PBDHMs have been proposed since the blueprint of PBDHMs was published by Freeze and Harlan (1969). The first full PBDHM is regarded as the SHE model published in 1987 (Abbott et al., 1986a, b); the others include WATERFLOOD model (Kouwen, 1988), THALES model (Grayson et al., 1992), VIC model (Liang et al., 1994), DHSVM model (Wigmosta et al., 1994), CASC2D model (Julien et al., 1995), WetSpa model (Wang et al., 1997), GBHM model (Yang et al., 1997), WEP-L model (Jia et al., 2001), Vflo model (Vieux and Vieux, 2002), WEHY model (Kavvas et al., 2004, 2006), Liuxihe model (Chen et al., 2011), and more. However, at the same time, the so-called semi-distributed hydrological models have also been proposed, such as the SWAT model (Arnold et al., 1994), TOPMODEL model (Beven et al., 1995), HRCDHM model (Carpenter et al., 2001), and others, with model complexity between the lumped model and distributed model.

Model parameters are very important to all kinds of models as they will determine the model performances in flood forecasting. Most of the model parameters could not be measured directly; therefore, they need to be estimated by some kind of model parameter estimation technique (Madsen, 2003; Laloy et al., 2010; Leta et al., 2015). As the lumped model has limited model parameters, the optimization technique has long been employed to calibrate the model parameters to improve the model's performance. For example, Dowdy et al. (1965) conducted a preliminary research on the parameter automatic optimization. Nash et al. (1970) and O'Connell et al. (1970) put forward a method to evaluate the accuracy of model simulation by utilizing efficiency coefficient. Ibbitt et al. (1971) designed a conceptual watershed hydrological model parameter fitting method. Duan et al. (1994) proposed the shuffled complex evolution (SCE) algorithm. Eberhart et al. (1995) proposed the particle swarm optimization method. Jasper et al. (2003) proposed the shuffled complex evolution metropolis algorithm-University of Arizona (SCEM-UA) method. Chu et al. (2011) proposed the shuffled complex evolution with principal components
analysis-University of California Irvine(SP-UCI) method. However, there are others. Now lots of parameter optimization methods for lumped hydrological models have been developed.

There are also many studies on parameter optimization for semi-distributed hydrologic models. Among them, the most studied model is SWAT due to its open-access codes and simple model structures. For example, the SCE-UA method was used to calibrate SWAT model for streamflow estimation (Ajami et al., 2004). The remote-sensing-derived evapotranspiration is used to calibrate the SWAT parameters by using Gauss-Marquardt-Levenberg algorithm (Immerzeel et al., 2008), and a multi-site calibration method with GA algorithm is also proposed for calibrating the SWAT parameters (Zhang et al., 2008). For estimating the parameters of Hydrology Laboratory Distributed Hydrologic Model, the regularization method was studied (Pokhrel et al., 2008).

PBDHMs usually have very complex model structures, and the hydrological processes are calculated by using physical meaning equations, so running a PBDHM is very timeconsuming compared to the lumped model. In addition, PBDHM sets different model parameters to different cells, so the total model parameters of a PBDHM are huge even for a small catchment. This makes it difficult to calibrate the PBDHM parameters like calibration widely exercised in lumped models. In the early stage of PBDHMs, the PBDHMs are assumed to derive model parameters from the terrain properties directly, so there is no need to calibrate model parameters. This is true, and all the proposed PBDHMs could determine the model parameters with their own methods (Refsgaard, 1997; De Smedt et al., 2000; Vieux et al., 2002; Chen, 2009). It is fair when they are used to study the future impacts of the hydrological processes caused by climate changes, or by terrain changes due to human activities, in which there are no observation data to evaluate the model performance or to calibrate the model parameters. Here, the hydrological process simulation/prediction accuracy is not so important; detection of the changing trends is the key issue. However, like the lumped model, parameter uncertainty still exists in PBDHMs, and parameter optimization is still needed to reduce this uncertainty (Gupta et al., 1998; Madsen, 2003; Vieux and Moreda, 2003; Reed et al., 2004; Smith et al., 2004; Pokhrel et al., 2012), particularly for those applications with high prediction accuracy requirement, such as the catchment flood forecasting. The scalar method (Vieux et al., 2004; Vieux, 2004) proposed to adjust Vflo model parameters in its application to flood forecasting could be regarded as the first exploration of PBDHM parameter optimization. In this method, all parameters are adjusted manually with a factor or a multiplicator (scalar) based on the initially derived parameters from the terrain properties. The scalars for the same parameter in different cells take the same values, so the parameters to be adjusted are only a few. This is feasible computationally and proven to be effective. For MIKE SHE model, an automatic parameter optimization method with SCE (Duan et al., 
1994) was employed in simulating catchment runoff (Madsen, 2003), which considers two objectives: fitting the surface runoff at the catchment outlet and minimizing the error on simulated underground water level at different wells. In the Liuxihe model, a half-automated method was proposed to adjust the model parameter (Chen, 2009; Chen et al., 2011). In simulating a medium-sized catchment runoff processes with WetSpa Model, a multi-objective genetic algorithm was used to optimize the WetSpa parameter (Shafii and De Smedt, 2009). Compared with lumped model and semi-distributed model, studies on parameter optimization of PBDHMs are very few, particularly for their uses in flood forecasting. Further work needs to be done in this regard.

Current optimization methods are mainly used in lumped hydrological model parameter calibration, which could be divided into two categories: global optimization and local optimization (Sorooshian et al., 1995). Local optimization method searches the parameter starting from a given initial parameter value with a fixed step length step by step, such as the simplex method (Nelder et al., 1965), Rosenbrock method (Rosenbrock, 1960), pattern search method (Hooke and Jeeves, 1961), among others. Local optimization methods are widely applied in the early stage (Sorooshian et al., 1983; Hendrickson et al., 1988; Franchini et al., 1996), but using local optimization method it is difficult to find the global optimum parameters. Lots of global optimization methods have been proposed since then for lumped models in the past decades after realizing the disadvantages of the local optimization method, such as the genetic algorithm (Holland et al., 1975; Goldberg et al., 1989), adaptive random search (Masri et al., 1980), simulated annealing (Kirkpatrick et al., 1983), ant colony system (Dorigo et al., 1996), shuffled complex evolution algorithm (SCE) (Duan et al., 1994), differential evolution (DE) (Storn and Price, 1997), particle swarm optimization (PSO) algorithm (Eberhart et al., 2001), SCEMUA (Jasper et al., 2003), SP-UCI (Chu et al., 2011), AMALGAM (Vrugt and Robinson, 2007), among others. Global optimization methods have been widely studied and applied in lumped model parameter calibration, with SCE and PSO the most widely used algorithms. SCE has been used for parameter optimization of Mike SHE (Madsen, 2003; Shafii and De Smedt, 2009), but PSO has never been used for PBDHM parameter optimization. PSO algorithm has the advantages of flexibility, easy implementation and efficiency (Poli et al., 2007; Poli, 2008); it has the potential to be employed to optimize the PBDHMs parameters.

There are two main purposes for this study: the first is to propose a parameter optimization method for PBDHMs in catchment flood forecasting by using PSO algorithm and to test its competence and improve its performances; the second is to explore the possibility of improving PBDHM capability in catchment flood forecasting by parameter optimization (i.e., whether PBDHM parameter optimization could improve model performance significantly and become achievable). In this paper, based on the scalar concept, a general framework for parameter optimization of the PBDHMs for catchment flood forecasting is first proposed that could be used for all PBDHMs. Then, with the Liuxihe model as the study model, which is a physically based distributed hydrological model proposed for catchment flood forecasting, the improved particle swarm optimization (PSO) algorithm is developed for the parameter optimization of the Liuxihe model in catchment flood forecasting. The method has been tested in two catchments in southern China with different sizes, and the results show that the improved PSO algorithm could be used for the Liuxihe model parameter optimization effectively and could improve the model capability largely in catchment flood forecasting.

\section{Methodology}

Based on the scalar concept, a general methodology for parameter optimization of the physically based distributed hydrological model for catchment flood forecasting is proposed, which is applicable to all physically based distributed hydrological models. This methodology has three steps: parameter classification, parameter initialization and normalization, and automated parameter optimization.

\subsection{Parameter classification}

In physically based distributed hydrological models, the whole terrain is divided into large numbers of grid cells. The model parameters in each cell are different, so the total parameter number is huge. The methodology proposed in this paper classifies the parameters into a few types, so as to reduce the parameter numbers needed to be optimized.

It is assume that all model parameters of a PBDHM are related and only related to one physical property of the terrain they belong - including the topography, soil type and vegetation type. Then the parameters of a PBDHM could be classified as four types: the climate-related parameters, the topography-related parameters, the vegetation-related (landuse-related) parameters and soil-related parameters. This classification could be used for all PBDHMs. With this classification, the parameters in different cells will have the same values if they have the same terrain properties. The independent parameters are defined based on this classification (i.e., the independent parameters are the parameters with the same terrain properties in each cell), and only the independent parameters need to be estimated and optimized. With this treatment, the number of model parameters with their values needed to be estimated will be largely reduced (i.e., from millions to tens), so the independent parameters could be optimized by employing optimization methods.

\subsection{Parameter initialization and normalization}

After classifying the model parameters into independent parameters, the feasible values of all the independent param- 
eters will be derived from the terrain properties directly. These values, in this paper, are called the initial values of the model parameters. As mentioned above, all proposed PBDHMs have their own methods to determine the initial model parameters.

Then the parameters are normalized with the initial values as follows:

$x_{i}=x_{i}^{\prime} / x_{i 0}$,

where $x_{i}^{\prime}$ is the original value of parameter $i, x_{i 0}$ is the initial value of parameter $i$, and $x_{i}$ is the normalized value of parameter $i$. With this normalization, all parameters become no-unit variables.

\subsection{Automated parameter optimization}

The normalized independent parameters will be automatically optimized with optimization methods. To do this, two important things need to be determined. The first one is to choose an optimization technique. In this study as mentioned above, the PSO algorithm will be employed. The second thing is to choose the optimization criterion (objective function). Different objective functions will result in different model parameters, thus different model performances. There are two main practices: the single-objective function and multiple-objective functions (Tang et al., 2006). Singleobjective optimization uses one objective function in the parameter optimization. This is the prevailing practice for both lumped model and distributed model parameter optimization. Multiple-objective optimization considers simultaneously two or more objective functions. The different objectives could have same measures quantitatively, such as to minimize the model efficiency and model efficiency for logarithmic transformed discharges simultaneously (Shafii and De Smedt, 2009), or even have different measures quantitatively, such as to minimize the streamflow simulation error and the well water lever simulation error simultaneously (Madsen, 2003). Not producing one set of optimal parameters like in single-objective optimization, multiple-objective optimization produces Pareto-optimal parameter sets. Each Pareto-optimal parameter is a feasible parameter, which provides the user the opportunity to trade off among different simulation purposes. For example, if the user wants to have a better simulation to the high flow of the streamflow, then the high weight will be given to the model efficiency. However, if a better simulation to the low flow is expected, then the priority should be put on the model efficiency for logarithmic transformed discharges (Shafii and De Smedt, 2009). Multiple-objective optimization is more flexible than singleobjective optimization, but it requires much more computation; if the model simulation purpose is determined (i.e., the objective is known), then the single-objective optimization is enough. In this study, the purpose is to optimize the model parameter for flood forecasting, so the purpose is obvious. The one objective function to minimize the peak flow rela- tive error of the catchment discharge at outlet is chosen, and the single-objective optimization is carried out.

\subsection{Liuxihe model and parameter classification}

The Liuxihe model (Chen, 2009; Chen et al., 2011) is a physically based distributed hydrological model mainly for catchment flood forecasting. In the Liuxihe model, the studied area is divided into a number of cells horizontally by using a DEM. The cells are called a unit basin, and they are treated as a uniform basin in which elevation, vegetation type, soil characteristics, rainfall, and thus model parameters are considered to take the same value. The unit basin is then divided into three layers vertically: the canopy layer, the soil layer and the underground layer. The boundary of the canopy layer is from the terrain surface to the top of the vegetation. The evapotranspiration takes place in this layer, and the evapotranspiration model is used to determine the evapotranspiration at the unit-basin scale. In the soil layer, soil water is filled by the precipitation and depleted via evapotranspiration. The underground layer is beneath the soil layer with a steady underground flow that is recharged by percolation. All cells are categorized into three types, namely hillslope cell, river cell and reservoir cell.

There are five different runoff routings in the Liuxihe model: hillslope routing, river channel routing, interflow routing, reservoir routing and underground flow routing. Hillslope routing routes the surface runoff produced in one hillslope cell to its neighboring cell, and the kinematic wave approximation is employed to make this routing. For the river channel routing, the shape of the channel cross section is assumed to be trapezoid, which makes it estimated by satellite images. The one-dimensional diffusive wave approximation is employed to make this routing.

The parameters in the Liuxihe model are divided into unadjustable parameters and adjustable parameters. The flow direction and slope are unadjustable parameters which are derived from the DEM directly and remain unchanged. The other parameters are adjustable parameters and could be adjusted to improve the model performance. The adjustable parameters are classified as four types: climate-based parameters, topography-based parameters, vegetation-based parameters and soil-based parameters. Currently in the Liuxihe model, there is method for determining initial values of adjustable parameters, and then the adjustable parameters are optimized by a half-automated parameter adjusting method (i.e., based on the initial parameter values, the parameter values are adjusted by hand to improve the model performance, and the parameter adjustment is done one parameter by one parameter). In this way, it is very tedious and timeconsuming. It takes months to adjust the parameters even in a very small catchment, so it is not highly proficient though it could improve the model performance. It is also not a global optimization method. An automatic, global optimization method of the Liuxihe model is needed. In this study, the 
Liuxihe model will be employed as the representative PBDHM.

\subsection{Improved PSO algorithm for the Liuxihe model}

\subsubsection{Principles of particle swarm optimization (PSO)}

Particle swarm optimization (PSO) algorithm was first proposed by American psychologist James Kennedy and electrical engineer Russell Eberhart (1995) during their study on the social and intelligent behaviors of a school of birds in their search for food and better living conditions. Now it is widely used in parameter calibration of lumped hydrological model. Resffa et al. (2013) used the PSO algorithm to optimize strategies for designing the membership functions of fuzzy control systems for the water tank and inverted pendulum. Mauricio et al. (2013) used the PSO optimization software for SWAT model calibration. Zambrano-Bigiarin et al. (2013) developed a hydroPSO software for model parameter optimization. Bahareh et al. (2013) used single-objective and multi-objective PSO algorithms to optimize parameters of Hydrologic Engineering Center-Hydrologic Modeling System(HEC-HMS) model. Leila et al. (2013) employed a multi-swarm version of particle swarm optimization (MSPSO) in connection with the well-known Hydrologic Engineering CenterHydrologic Modeling System(HEC-HMS) simulation model in a parameterization-simulation-optimization (parameterization SO) approach. Richard et al. (2014) compared the PSO algorithm with other algorithms in hydrological model calibration. Jeraldin et al. (2014) used PSO in the tank system. These PSO applications are for lumped models only.

PSO is a global searching algorithm in which each particle represents a feasible solution to the model parameters, and usually an appropriate number of particles is chosen to act like a school of birds. The appropriate number of particles is a very important PSO parameter that will impact the PSO's performance. In the optimization process, these particles move forward over the searching space at the same time following certain rules - which include each particle's moving direction and moving speed - that can be determined with the following equations.

$$
\begin{aligned}
& V_{i, k}=\omega \times V_{i, k-1}+C_{1} \times \text { rand } \times\left(X_{i, \mathrm{pBest}}-X_{i, k-1}\right) \\
& +C_{2} \times \text { rand } \times\left(X_{\mathrm{gBest}}-X_{i, k-1}\right) \\
& X_{i, k}=X_{i, k-1}+V_{i, k},
\end{aligned}
$$

where $V_{i, k}$ is the moving speed of $i$ th particle at $k$ th step, $X_{i, k}$ is the position of $i$ th particle at $k$ th step, $X_{i, \mathrm{pBest}}$ is the best position of $i$ th particle at $k$ th step (current), $X_{\text {gBest }}$ is the best position of all particles at $k$ th step, $\omega$ is inertia acceleration speed, $\mathrm{C} 1$ and $\mathrm{C} 2$ are learning factors, and rand is a random number between 0 and 1 . Here $\omega, \mathrm{C} 1$ and $\mathrm{C} 2$ are also important PSO parameters that will impact the PSO's performance.

For one-step optimization, also called one evolution, all particles move forward one step. All particles will then have their best positions up to now, and the best position of all particles represents the global optimal positions of all particles. With step-by-step evolution, the global positions of all the particles will be approached, and the corresponding parameter values are the optimal parameter values. In the evolution process, a maximum number of evolution is usually set to keep the optimization process to a reasonable time limit.

\subsubsection{Improved PSO algorithm}

In the early PSO algorithm, particle number, $\omega, \mathrm{C} 1$ and $\mathrm{C} 2$ are fixed. Studies show that changing the values of $\omega, \mathrm{C} 1$ and $\mathrm{C} 2$ in the PSO search process will improve the PSO's performance (El-Gohary et al., 2007; Song et al., 2008; Acharjee et al., 2010; Chuang et al., 2011). In this study, current research progress in improving PSO's performance will be introduced to improve PSO algorithm. The strategies employed in changing $\omega, \mathrm{C} 1$ and $\mathrm{C} 2$ are stated below and will be tested in the studied catchments. In this paper, the appropriate PSO particle number, $\omega, \mathrm{C} 1$ and $\mathrm{C} 2$ are called PSO parameters.

\section{Inertia weight $\omega$}

The inertia weight $\omega$ is a PSO parameter impacting the global search capability (Shi and Eberhart, 1998). In the earlier studies, $\omega$ takes a fixed value of less than 1 . Current studies show that changing $\omega$ could improve the PSO performance, and a few methods for dynamically adjusting $\omega$ have been proposed, such as linearly decreasing inertia weight strategy (LDIW) (Shi and Eberhart, 2001), adaptive adjustment strategy (Ratnaweera et al., 2004), random inertia weight (RIW) (Shu et al., 2009) and fuzzy inertia weight (Eberhart and Shi, 2001). In this study, the LDIW strategy is employed to dynamically determining the value of $\omega$ with the following equation:

$\omega=\omega_{\max }-\frac{i\left(\omega_{\max }-\omega_{\min }\right)}{\operatorname{MaxN}}$,

where $i$ is the current evolution number, MaxN is the maximum evolution number, $\omega_{\max }$ takes the value of 0.9 and $\omega_{\min }$ takes the value of 0.1 .

\section{Acceleration coefficients $\mathrm{C} 1$ and $\mathrm{C} 2$}

Acceleration coefficients $\mathrm{C} 1$ and $\mathrm{C} 2$ also impact PSO's performance. In early studies, acceleration coefficients $\mathrm{C} 1$ and C2 usually take the same value of 2, and they are fixed in the evolution process. Studies show that dynamically adjusting $\mathrm{C} 1$ and $\mathrm{C} 2$ and taking different values for $\mathrm{C} 1$ and $\mathrm{C} 2$ could improve PSO's performances, and a few methods have been proposed, such as the linear strategy (Ratnaweera et al., 2004), concave function strategy (Chen et al., 2006) and arccosine function strategy (Chen et al., 2007). In this study, the arccosine function strategy is employed to determine the 
values of $\mathrm{C} 1$ and $\mathrm{C} 2$. The equations are listed below.

$$
\begin{aligned}
& c_{1}=c_{1 \text { min }}+\left(c_{1 \text { max }}-c_{1 \text { min }}\right)\left(1-\frac{\arccos \left(\frac{-2 \times i}{\operatorname{MaxN}}+1\right)}{\pi}\right) \\
& c_{2}=c_{2 \max }-\left(c_{2 \max }-c_{2 \min }\right)\left(1-\frac{\arccos \left(\frac{-2 \times i}{\operatorname{MaxN}}+1\right)}{\pi}\right),
\end{aligned}
$$

where $C_{1 \max }$ and $C_{1 \text { min }}$ are the maximum and minimum value of $C_{1}$. The values of 2.75 and 1.25 are recommended. $C_{2 \max }$ and $C_{2 \min }$ are the maximum and minimum values of $C_{2}$, and the values of 2.5 and 0.5 are recommended. $i$ is the current evolution number. MaxN is the maximum evolution number.

\section{.3 PSO procedure}

The parameter optimization method based on PSO is summarized below.

1. Choose the independent parameters to be optimized. In the case that the computation load is a great challenge, only highly sensitive parameters will be optimized; otherwise, all parameters could be optimized.

2. Initialize independent parameters to be optimized and normalize them.

3. Choose optimization criterion, particle number, maximum evolution number, $\omega, \mathrm{C} 1$ and $\mathrm{C} 2$.

4. Initialize all particles (i.e., determine their initial positions, and calculate the value of the current objective function).

5. For every evolution, first determine the best position of every particle and the global positions of all particles; then calculate the moving directions and speeds of every particles at current evolution by using Eqs. (2) and (3). Finally, check the optimization criterion. If it is satisfied, then the optimization ends. Otherwise, continue to the next evolution.

\section{Studied catchment and the Liuxihe model setup}

\subsection{Studied catchment and hydrological data}

Two catchments in southern China have been selected as the case study catchments. The first catchment is Tiantoushui catchment in Lechang County of Guangdong Province. It is a small watershed with a drainage area of $511 \mathrm{~km}^{2}$ and channel length of $70 \mathrm{~km}$, which is a typical mountainous catchment with frequent flash flooding in southern China. Tiantoushui catchment will mainly be used to test the PSO parameter impacts on the algorithm performance, so as to propose the optimal PSO parameters for the Liuxihe model parameter optimization. As this work needs lots of model runs, a small
Table 1. Initial values of land-use-based parameters in Tiantoushui catchment.

\begin{tabular}{llll}
\hline ID & Name & $\begin{array}{l}\text { Evaporation } \\
\text { coefficient }\end{array}$ & $\begin{array}{l}\text { Roughness } \\
\text { coefficient }\end{array}$ \\
\hline 2 & evergreen coniferous forest & 0.7 & 0.4 \\
3 & evergreen broadleaved forest & 0.7 & 0.6 \\
5 & shrub & 0.7 & 0.4 \\
15 & cultivated land & 0.7 & 0.35 \\
\hline
\end{tabular}

catchment helps to keep the running time to a feasible limit. There are 50 rain gauges within the catchment and one river flow gauge in the catchment outlet. The high-density rain gauge network is built not only for flash flood forecasting but also for some kinds of scientific experiments. This will also help to reduce the uncertainties caused by the uneven precipitation spatial distribution. Figure 1a is the sketch map of Tiantoushui catchment with locations of rain gauges and the tributaries.

Hydrological data of nine flood events have been collected for this study, including the river flow at the catchment outlet and precipitation at each rain gauges at an hourly interval. The precipitation measured by the rain gauges will be interpolated to the grid cells by employing Thiessen polygon method (Derakhshan et al., 2011).

The second studied catchment is the upper portion of $\mathrm{Wu}-$ jiang catchment in southern China. It is called in this paper the upper and middle Wujiang catchment (UMWC). UMWC is in the upper and middle stream of Wujiang catchment with a drainage area of $3622 \mathrm{~km}^{2}$. Flooding in the catchment is also very frequent and heavy. The purpose of studying this big catchment is to show that PSO could still work in a large catchment. There is one river flow gauge in the outlet of UMWC and 17 rain gauges within the catchment. Figure $1 \mathrm{~b}$ shows the sketch map of the catchment with locations of rain gauges and the tributaries. Hydrological data of 14 flood events from UMWC have been collected, including the river flow at the catchment outlet and precipitation at each rain gauges at $1 \mathrm{~h}$ interval. The precipitation measured by the rain gauges will also be interpolated to the grid cells employing Thiessen polygon method.

\subsection{Property data for the Liuxihe model setup}

Catchment property data used for model setup in this study are DEM, land use types and soil types. These data of the studied catchments were downloaded from an openaccess databases. The DEM was downloaded from the Shuttle Radar Topography Mission database at http://srtm.csi. cgiar.org. The land use type was downloaded from http: //landcover.usgs.gov, and the soil type was downloaded from http://www.isric.org. The downloaded DEM has a spatial resolution of $90 \mathrm{~m} \times 90 \mathrm{~m}$, but the other two data sets have a spatial resolution of $1000 \mathrm{~m} \times 1000 \mathrm{~m}$, so they are rescaled to 


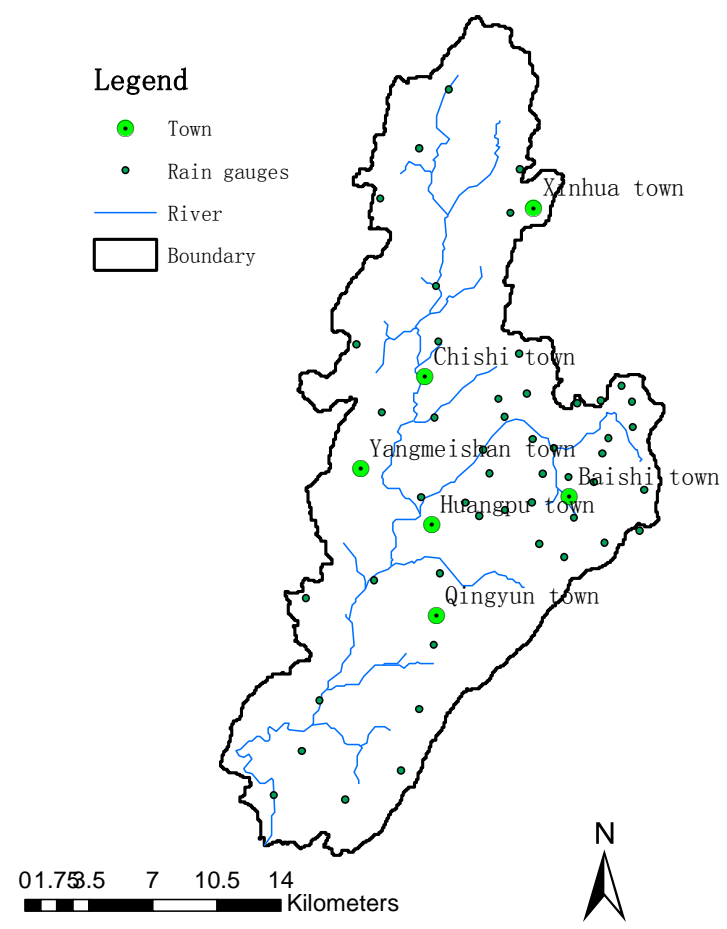

(a) Tiantoushui Catchment

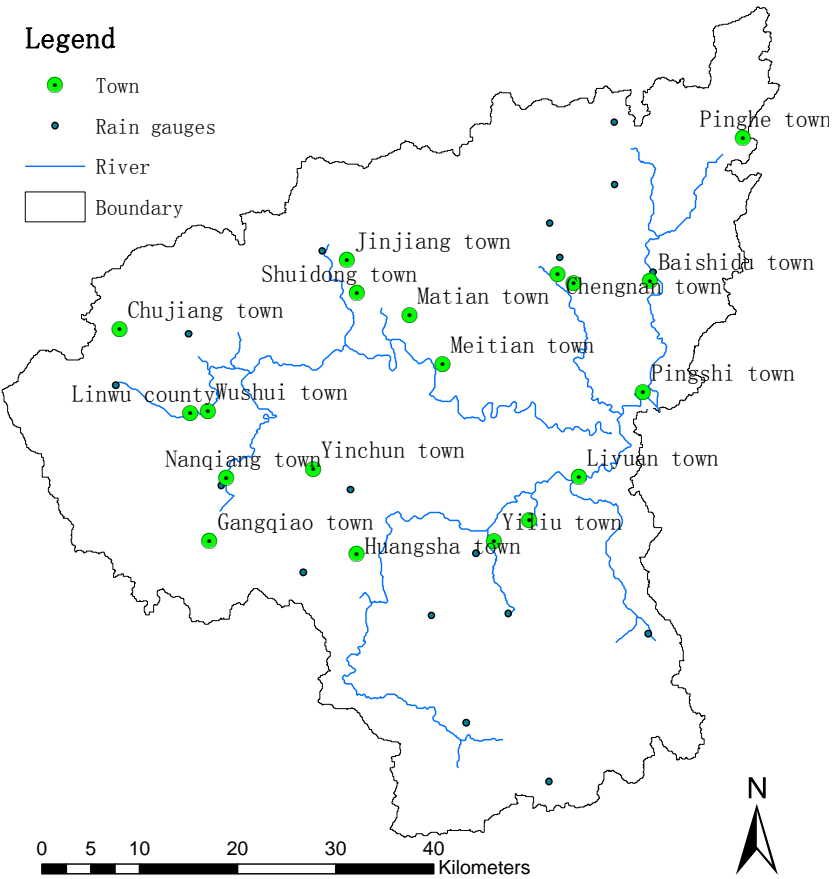

(b) Upper and middle Wujiang Catchment(UMWC)

Figure 1. Sketch map of the studied catchments: (a) Tiantoushui catchment and (b) upper and middle Wujiang catchment (UMWC).

the spatial resolution of $90 \mathrm{~m} \times 90 \mathrm{~m}$. Figures 2 and 3 show the property data of DEM, land use types and soil types of the two catchments respectively.
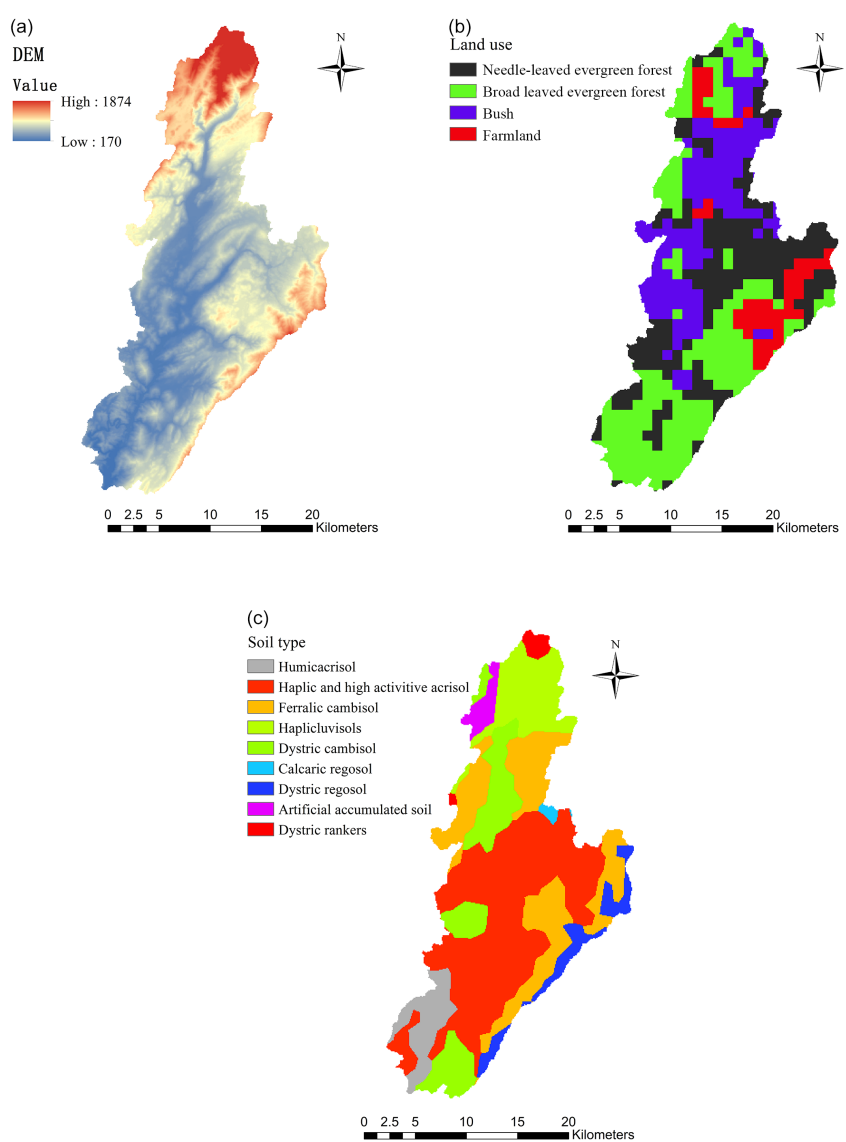

Figure 2. Terrain properties of Tiantoushui catchment: (a) DEM, (b) land use type and (c) soil type.

In the Tiantoushui catchment, the highest, lowest and average elevation are 1874, 174 and $782 \mathrm{~m}$ respectively. There are four land use types - evergreen coniferous forest, evergreen broadleaved forest, bush and farmland - accounting for $27.6,36.5,25.5$, and $10.4 \%$ of the total catchment area respectively. There are 10 soil types - water body, Humic Acrisol, Haplic and highly active Acrisol, Ferralic Cambisol, Haplic Luvisols, Dystric Cambisol, Calcaric Regosol, Dystric Regosol, Artificial accumulated soil and Dystric rankers - accounting for $4.8,56.5,1.7,3.4,6.5,4.5,0.7,5.6,9.8$ and $6.5 \%$ of the total catchment area respectively.

In the UMWC catchment, the highest, lowest and average elevation are 1793, 170 and $982 \mathrm{~m}$ respectively. There are eight land use types - evergreen coniferous forest, evergreen broadleaved forest, shrub, sparse wood, mountains and alpine meadow, slope grassland, lakes, and cultivated land accounting for $26.4,24.3,35,2.1,0.1,2.6,0.5$ and $9.1 \%$ of the total catchment area respectively. There are 12 soil types - water body, Humic Acrisol, Haplic and highly active Acrisol, Ferralic Cambisol, Haplic Luvisols, Dystric Cambisol, Calcaric Regosol, Dystric Regosol, Haplic and weakly active Acrisol, artificial accumulated soil, Eutric Regosols and black limestone soil and dystric rankers - accounting for 

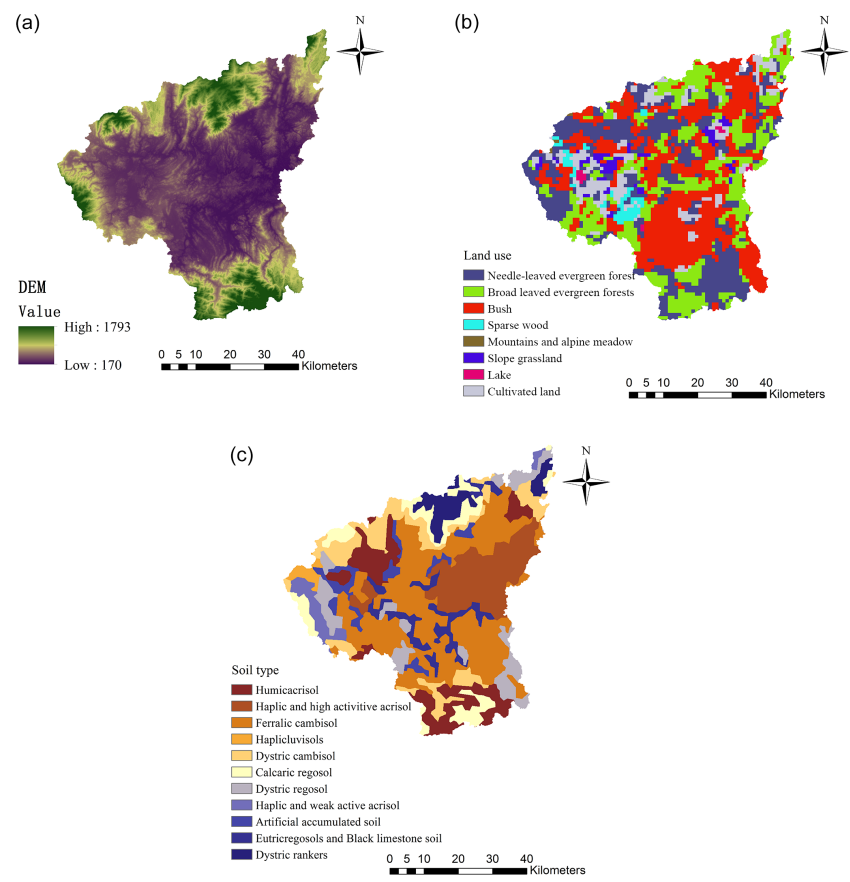

Figure 3. Terrain property data of UMWC: (a) DEM, (b) land use type and (c) soil type.

$4.8,56.5,0.5,3.4,6.5,4.5,0.7,5.6,9.8,6.6,1.0$ and $0.2 \%$ of the total catchment area respectively.

\subsection{Liuxihe model setup}

Setting up the Liuxihe model in the studied catchments consists of dividing the whole catchment into grids with DEM. In this study, the Tiantoushui catchment is divided into 65011 grid cells using the DEM with grid cell size of $90 \mathrm{~m} \times 90 \mathrm{~m}$; then they are categorized into reservoir cell, river channel cell and hillslope cell. In the studied catchments, there are no significant reservoirs, so there are no reservoir cells set. Based on the method for cell type classification proposed in the Liuxihe model, the river channel system is treated as a third-order channel system, and 1364 river channel cells and 63647 hillslope cells have been produced in Tiantoushui catchment respectively. Further, 10 nodes have been set on the Tiantoushui catchment, and the river channel system is divided into 14 virtual sections. Their cross section sizes have been estimated by referencing to satellite remote-sensing images. The Liuxihe model structure of Tiantoushui catchment is shown in Fig. 4a.

The Liuxihe model is also set up in UMWC. The catchment is first divided into 460695 grid cells using the DEM with grid cell size of $90 \mathrm{~m} \times 90 \mathrm{~m}$. The river channel system is treated as a third-order channel system, and 3295 river channel cells and 457400 hillslope cells have been produced respectively; 32 nodes have been set on UMWC, and their cross-section sizes have been estimated by referencing to satellite remote sensing images. The Liuxihe model structure of UMWC is shown in Fig. 4b.

\subsection{Determination of initial parameter values}

In the Liuxihe model, the flow direction and slope are two unadjustable parameters which will be derived from the DEM and will remain unchanged. Based on the DEM shown in Fig. 1a, the flow direction and slope of the studied catchments are derived. The other parameters are adjustable parameters, which need initial values for further optimization. Evaporation capacity is a climate-based parameter, and its initial value is set to $5 \mathrm{~mm} \mathrm{~d}^{-1}$ at both catchment based on the observation near the catchment outlet. Evaporation coefficient and roughness are land-use-based parameters and are less sensitive parameters in the Liuxihe model. The initial values of evaporation coefficient are set to 0.7 at both catchments as recommended by the Liuxihe model (Chen, 2009), while the initial values of roughness are derived based on Wang et al. (1997) and are listed in Tables 1 and 2 respectively for the two catchments.

The other parameters are soil-based parameters. In the Liuxihe model, $b$ is recommended to take the value of 2.5 . Soil water content under wilting conditions takes $30 \%$ of the soil water content under saturated conditions. The initial values of other soil-based parameters are calculated by using the Soil Water Characteristics Hydraulic Properties Calculator (Arya et al., 1981), which calculates soil water content at saturation and field condition and the hydraulic conductivity at saturation based on the soil texture, organic matter, gravel content, salinity and compaction. The initial values of soil-based parameters are determined by using the program developed by Keith E. Saxton that can be downloaded for free at http://hydrolab.arsusda.gov/soilwater/Index.htm. The initial values of the soil-based parameters at the two studied catchments are listed in Tables 3 and 4 respectively.

\section{Discussion and results}

\subsection{Impacting of particle number to PSO performance and the determination of appropriate particle number}

Particle number is an important parameter of PSO, to understand the impact of the particle number on the PSO performance and to determine the appropriate particle number. Six values of particle number - 10, 15, 20, 25, 50 and 100 - have been used to optimize the model parameters of the Liuxihe model setup in Tiantoushui catchment. While maximum evolution number is set to $50, \omega, \mathrm{C} 1$ and $\mathrm{C} 2$ are dynamically adjusted with Eqs. (4)-(6). Flood event flood2006071409 is used to do this calculation. Five evaluation indices - NashSutcliffe coefficient $C$, correlation coefficient $R$, process relative error $P$, peak flow relative error $E$ and the coefficient of water balance $W$ - have been computed and are listed in Ta- 
Table 2. Initial values of land-use-based parameters in UMWC.

\begin{tabular}{llll}
\hline ID & Name & $\begin{array}{l}\text { Evaporation } \\
\text { coefficient }\end{array}$ & $\begin{array}{l}\text { Roughness } \\
\text { coefficient }\end{array}$ \\
\hline 2 & Evergreen coniferous forest & 0.7 & 0.4 \\
3 & Evergreen broadleaved forest & 0.7 & 0.6 \\
5 & Shrub & 0.7 & 0.4 \\
6 & Sparse wood & 0.7 & 0.5 \\
7 & Mountains and alpine meadow & 0.7 & 0.2 \\
8 & Slope grassland & 0.7 & 0.3 \\
10 & Lakes & 0.7 & 0.05 \\
15 & Cultivated land & 0.7 & 0.35 \\
\hline
\end{tabular}

Table 3. Initial values of soil-based parameters in Tiantoushui catchment.

\begin{tabular}{|c|c|c|c|c|c|c|}
\hline Soil type & $\begin{array}{l}\text { Thickness } \\
(\mathrm{mm})\end{array}$ & $\begin{array}{l}\text { Saturated water } \\
\text { content }\end{array}$ & $\begin{array}{l}\text { Field } \\
\text { capacity }\end{array}$ & $\begin{array}{l}\text { Saturated hydraulic } \\
\text { conductivity }\left(\mathrm{mm} \mathrm{h}^{-1}\right)\end{array}$ & $\begin{array}{l}b \\
\text { (percentage) }\end{array}$ & wilting \\
\hline Humic Acrisol & 700 & 0.515 & 0.362 & 3 & 2.5 & 0.2 \\
\hline Haplic and highly active Acrisol & 1000 & 0.517 & 0.369 & 3 & 2.5 & 0.206 \\
\hline Ferralic Cambisol & 700 & 0.419 & 0.193 & 15 & 2.5 & 0.1 \\
\hline Haplic Luvisols & 1000 & 0.55 & 0.501 & 2 & 2.5 & 0.357 \\
\hline Dystric Cambisol & 820 & 0.385 & 0.164 & 34 & 2.5 & 0.076 \\
\hline Calcaric Regosol & 1000 & 0.5 & 0.324 & 3 & 2.5 & 0.172 \\
\hline Dystric Regosol & 950 & 0.388 & 0.169 & 33 & 2.5 & 0.077 \\
\hline Artificial accumulated soil & 1000 & 0.459 & 0.25 & 8 & 2.5 & 0.121 \\
\hline Dystric rankers & 150 & 0.43 & 0.203 & 10 & 2.5 & 0.113 \\
\hline
\end{tabular}

ble 5. The computation times for each optimization are also listed in Table 5.

We first analyze the impact of particle number on the computation time. From the results of Table 5 we found that with the increase of the particle number from 10 to 100 , the computation time used decreases first. However, when the particle number is bigger than 20, the computation time increases then, and when the particle number is 20 , the computation time is $12.1 \mathrm{~h}$, which is the shortest among others. This means that particle number impacts the computation time used in optimization. The small and big particle number is not the best particle number. There exists an appropriate particle number to make the optimization in the least amount of time. In the Tiantoushui catchment, 20 is an appropriate particle number from the view of computational efficiency.

We further analyze the impact of particle number on the model performances by comparing the five evaluation indices. From the results, an obvious trend could be found: with the increase of the particle number, the Nash-Sutcliffe coefficient $\mathrm{C}$, the correlation coefficient $R$ and water balance coefficient increase first, but when the particle number reaches 20 , the three indices decrease. However, for the process relative error $W$ and peak flow relative error $E$, the trend is inversed (i.e., with the increase of the particle number, the process relative error $W$ and peak flow relative error $E$ decrease first, but when the particle number reaches 20 , the two indices increase). This also means that, with the increase of the particle number, the model performance increases first and then decreases. So from the view of model performance, we could assume 20 is the appropriate particle number in the Tiantoushui catchment. So in this paper, from the results above, we could suggest that 20 is the appropriate particle number of PSO algorithm for the Liuxihe model in catchment flood forecasting in Tiantoushui catchment.

The particle number of 20 is also used in the parameter optimization of UMWC catchment, and the model performance is also very satisfactory. The computation time is acceptable, so in this study we assume that 20 is the appropriate particle number for the Liuxihe model parameter optimization when employing the PSO algorithm for catchment flood forecasting no matter the size of the catchment. This conclusion can also be derived from the results of PSO's convergence in the next section.

\subsection{PSO's convergence}

PSO algorithm is an evolution algorithm; its searching process is an iteration process, so the convergence is a key issue (i.e., the algorithm should converge to its optimal state in a limited iteration number). Otherwise, it could not be used practically. In PSO, the iteration is called evolution; one iteration is called one evolution. To explore PSO's convergence, we first draw the optimization evolution process of PSO in 
Table 4. Initial values of soil-based parameters in UMWC.

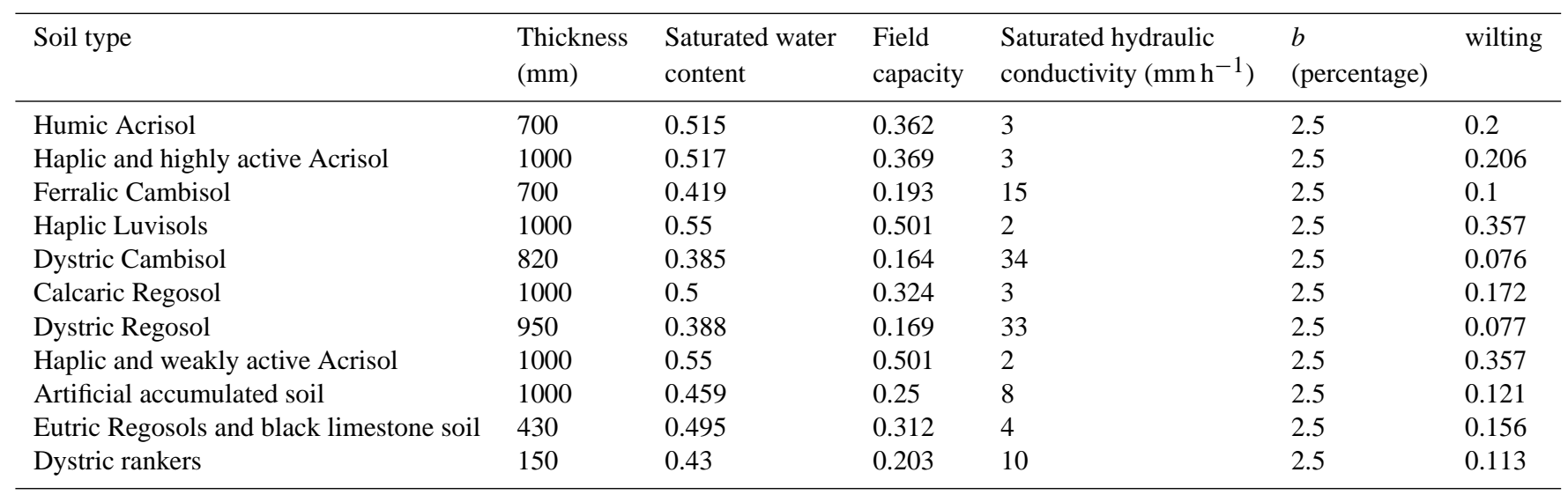

Table 5. Performances of PSO algorithm in Tiantoushui catchment.

\begin{tabular}{lllllll}
\hline $\begin{array}{l}\text { Particle } \\
\text { number }\end{array}$ & $\begin{array}{l}\text { Computation } \\
\text { time (h) }\end{array}$ & $\begin{array}{l}\text { Nash-Sutcliffe } \\
\text { coefficient } C\end{array}$ & $\begin{array}{l}\text { Correlation } \\
\text { coefficient } R\end{array}$ & $\begin{array}{l}\text { Process relative } \\
\text { error } P\end{array}$ & $\begin{array}{l}\text { Peak flow relative } \\
\text { error } E\end{array}$ & $\begin{array}{l}\text { Water balance } \\
\text { coefficient } W\end{array}$ \\
\hline 10 & 21 & 0.793 & 0.896 & 0.319 & 0.086 & 0.894 \\
15 & 13 & 0.849 & 0.925 & 0.235 & 0.077 & 0.903 \\
20 & 12.1 & 0.962 & 0.951 & 0.13 & 0.07 & 0.917 \\
25 & 18.6 & 0.852 & 0.927 & 0.237 & 0.056 & 0.884 \\
50 & 45 & 0.862 & 0.932 & 0.242 & 0.043 & 0.885 \\
100 & 86.8 & 0.838 & 0.92 & 0.256 & 0.054 & 0.867 \\
\hline
\end{tabular}

Tiantoushui catchment in Fig. 5. Both the objective and parameter evolution processes are included.

From Fig. 5 we found that, during the evolution process, the objective function steadily decreases, which means the model performance is constantly improved. But for all the parameters, they do not change in the same direction: the parameters may increase in one evolution and decrease in the next evolution. However, after more than 25 evolutions, most of the parameters converge to their optimal values. With about 30 evolutions, all of the parameters converge to their optimal values; after that, there are almost no parameter changes. This means 30 is the maximum evolution number for PSO in Tiantoushui catchment.

From Fig. 5, we also found that the optimal parameter values of several parameters are quite different with the initial parameters, but some remain little changes. This also implies that the PSO algorithm has very good performance in convergence. Even the initial values of the parameters are far from their optimal values.

We further analyze PSO's performance in UMWC, but this time we only draw the parameter evolution process of PSO in UMWC in Fig. 6. The objective evolution process of PSO in UMWC is similar to that in the Tiantoushui catchment.

From Fig. 6 we also found that, during the evolution process, the objective function steadily decreases, but the parameters do not increase or decrease in a constant way. The changing patten is similar to that shown in Fig. 5. After 25 evolutions, most of the parameters converge to their optimal values. With about 30 evolutions, all of the parameters converge to their optimal values. The patten in UMWC is the same as that in Tiantoushui catchment.

From Fig. 6, we also found that the optimal parameter values of several parameters are quite different from the initial values, but some remain little changes. This patten in UMWC is the same as that in Tiantoushui catchment also.

From the above results both in UMWC and Tiantoushui catchment, we could assume that PSO algorithm has a very good performance in convergence in catchments with different sizes, and we could assume that the maximum evolution number could be set to 30 no matter the size of the studied catchments. This conclusion also supports the conclusion that 20 is the appropriate particle number for the Liuxihe model parameter optimization when employing PSO algorithm for catchment flood forecasting no matter the size of the catchment.

\subsection{Computational efficiency}

The computation time needed for physically based distributed hydrological model run is huge. For the parameter optimization, many model runs are needed, so the computation time needed for the parameter optimization is also a key factor impacting the performance of the PSO. From Table 5, 


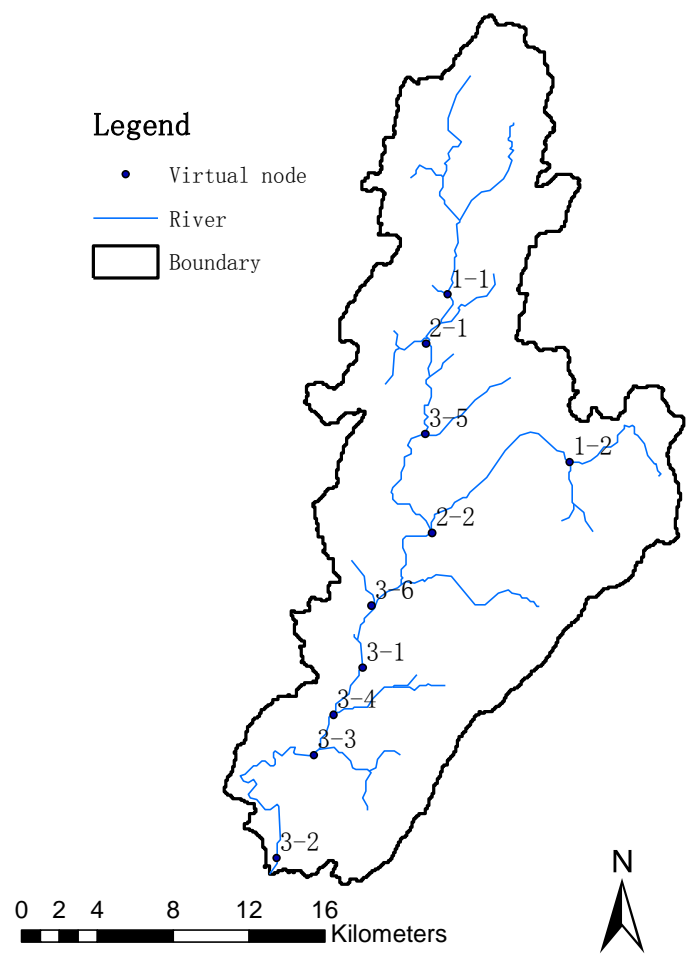

(a) Tiantoushui Catchment

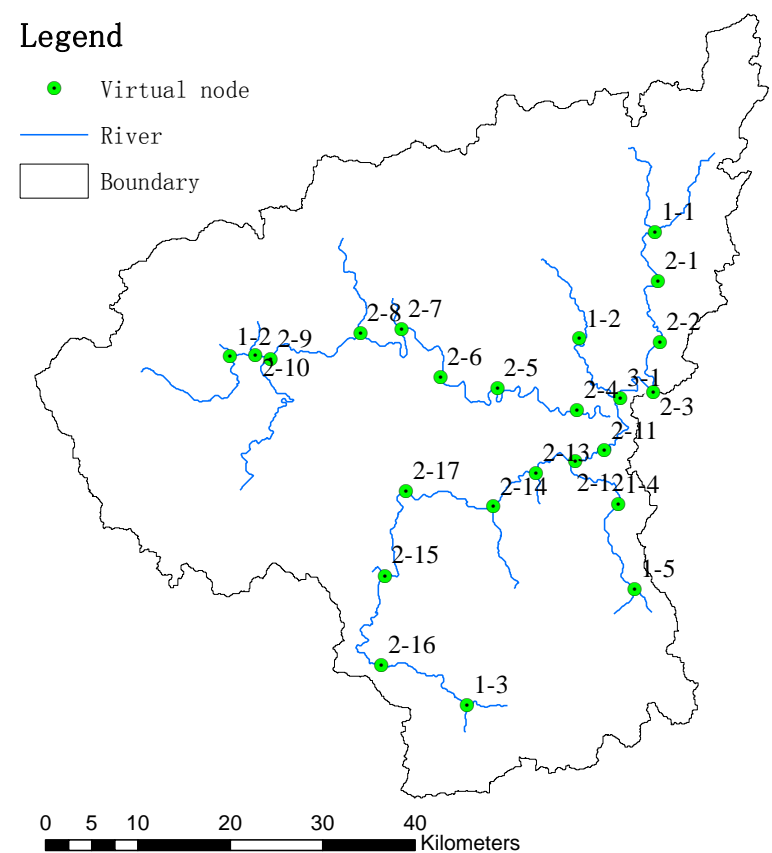

(b) UMWC Catchment

Figure 4. Model setup results: (a) Tiantoushui catchment and (b) UMWC catchment.

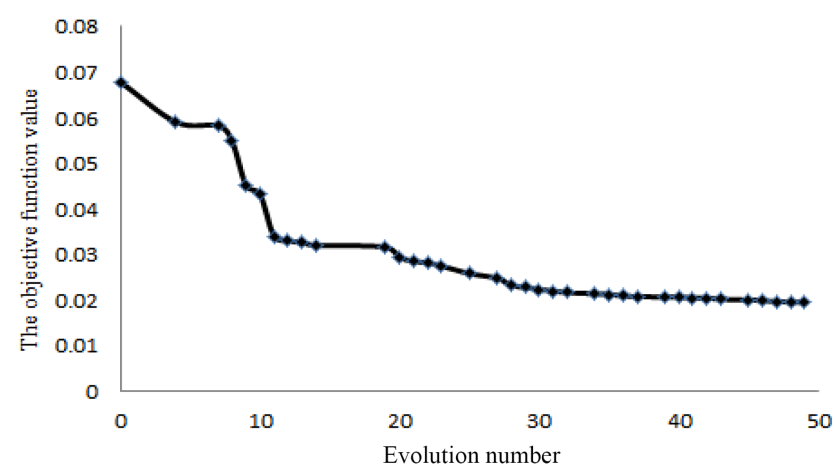

(a) Evolution of objective function

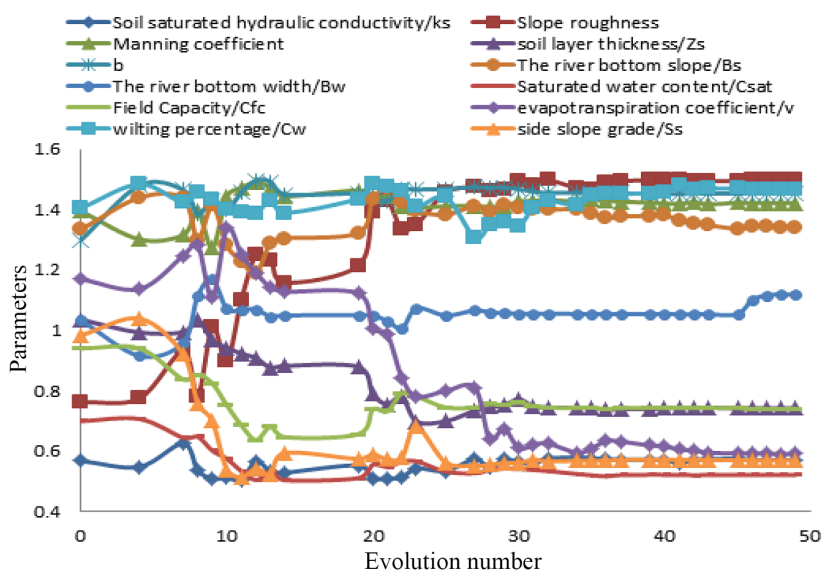

(b)Evolution of parameters

Figure 5. The evolution process of parameter optimization with PSO in Tiantoushui catchment: (a) evolution of objective function and (b) evolution of parameters.

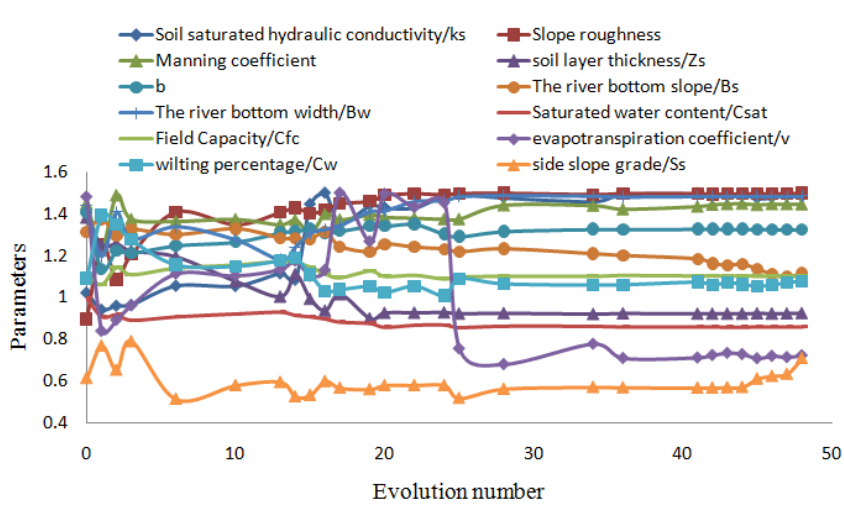

Figure 6. The evolution processes of parameter optimization with PSO in UMWC.

we know, in Tiantoushui catchment, the computation time for parameter optimization is about $12 \mathrm{~h}$; this is acceptable. The time needed for parameter optimization in UMWC is about $82.6 \mathrm{~h}$; it is also acceptable. The computer used for this study 


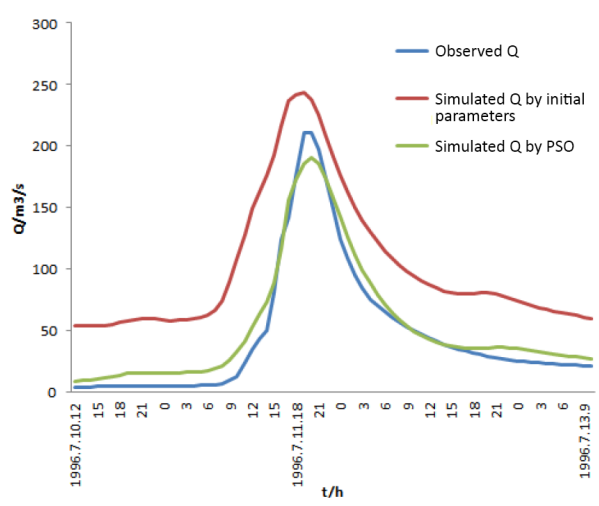

(a) Flood1996071012

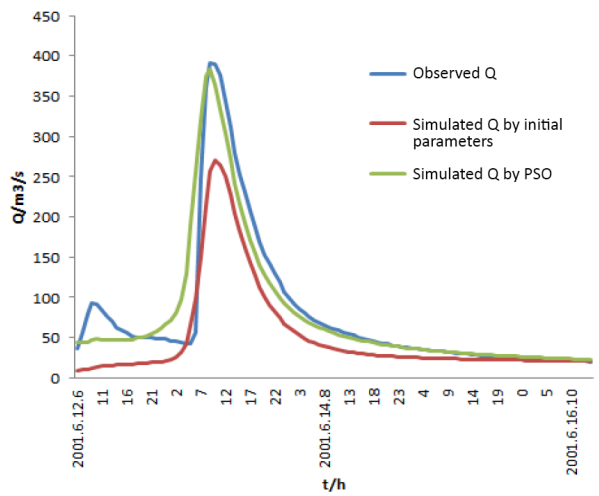

(b) flood2001061206

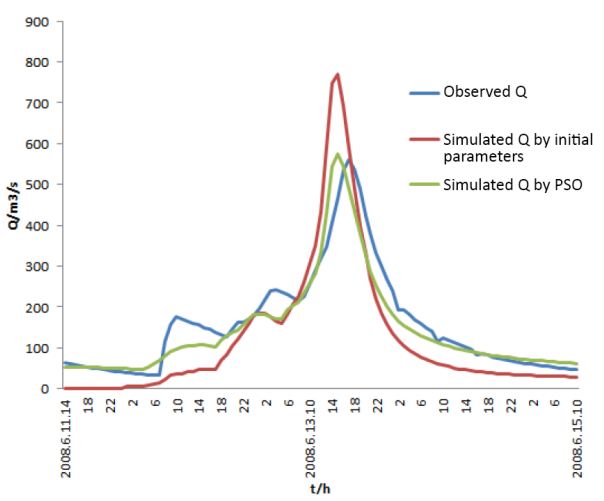

(c) flood 2008061114

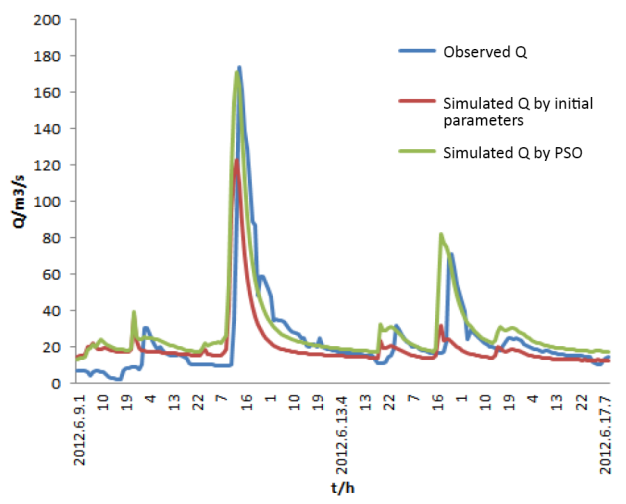

(d) flood2012060901

Figure 7. Simulated flood events of Tiantoushui Catchmen. (a) flood1996071012, (b) flood2001061206, (c) flood2008061114, (d) flood2012060901.

is a general server. If we used an advanced computer, the time needed could be reduced largely.

\subsection{Model validation in Tiantoushui catchment}

The parameters of the Liuxihe model in Tiantoushui catchment have been optimized by employing PSO algorithm proposed in this paper. The particle number used is 20 . Maximum evolution number is set to $50 ; \omega, \mathrm{C} 1$ and $\mathrm{C} 2$ are dynamically adjusted with Eqs. (4)-(6). Flood event flood2006071409 is used to optimize the parameters.

The other eight observed flood events of Tiantoushui catchment are simulated by the model with parameters optimized above to validate the model performance for catchment flood forecasting. To analyze the effect of parameter optimization to model performance improvement, Fig. 7 shows four of the simulated hydrographs. The hydrographs simulated by the model with initial parameter values are also drawn in Fig. 7.

From the results, it has been found that the eight simulated hydrographs fit the observed hydrographs well. Particularly the simulated peak flow is quite good. From the results we also found that the model with initial parameter values does not simulate the observed flood events satisfactorily (i.e., the uncertainties are high).

To further analyze the model performance with parameter optimization, the five evaluation indices of the eight simulated flood events have been calculated and are listed in Table 6 .

From Table 6 we found that the five evaluation indices have been improved by parameter optimization at different extents. For the results simulated by the model with initial parameters, the five evaluation indices - the Nash-Sutcliffe coefficient, correlation coefficient, process relative error, peak flow relative error and water balance coefficient - have average values of $0.66,0.85,72 \%, 21 \%$ and 1.03 respectively. For the results simulated by the model with optimized parameters, the five evaluation indices have average values of 0.88 , $0.94,25 \%, 6 \%$ and 0.97 respectively. The average NashSutcliffe coefficient has a $33 \%$ increase, the correlation coefficient a $9.6 \%$ increase, process relative error a $65.28 \%$ decrease, peak flow relative error a $71.43 \%$ decrease, and the water balance coefficient a $5.83 \%$ decrease. Among the five evaluation indices, the peak flow relative error and the process relative error have the biggest improvement.

The above results imply that with parameter optimization using the PSO algorithm proposed in this paper, the model 


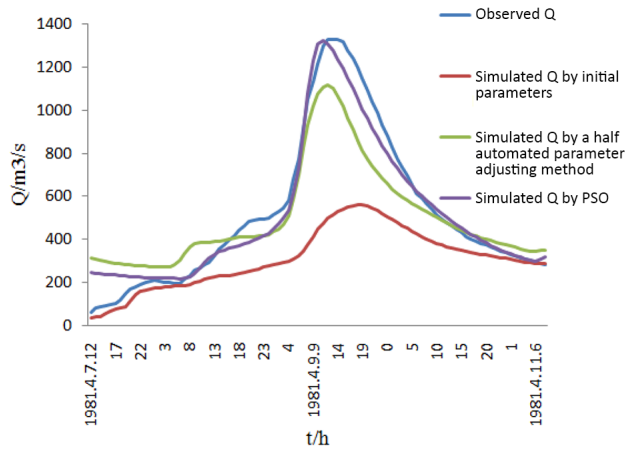

(a) flood 1981040712

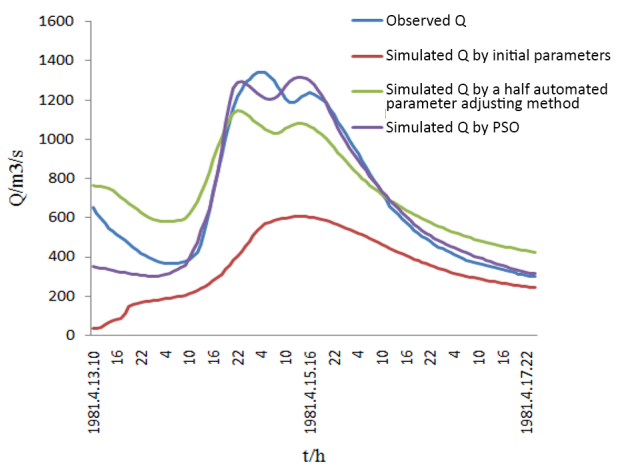

(b) flood 1981041310

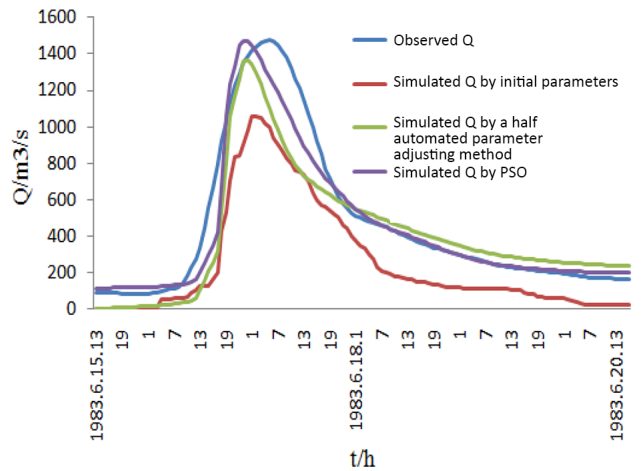

(c) flood1983022720

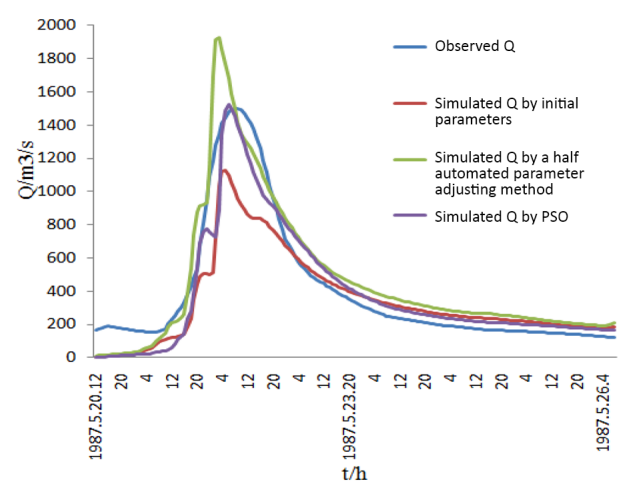

(d) flood1987052012

Figure 8. Simulated flood events of UMWC: (a) flood1981040712, (b) flood1981041310, (c) flood1983022720 and (d) flood1987052012.

Table 6. The evaluation index of the simulated flood events in Tiantoushui catchment.

\begin{tabular}{|c|c|c|c|c|c|c|c|c|c|c|}
\hline \multirow[b]{2}{*}{ Flood events } & \multicolumn{2}{|c|}{$\begin{array}{c}\text { Nash-Sutcliffe } \\
\text { coefficient } C\end{array}$} & \multicolumn{2}{|c|}{$\begin{array}{c}\text { Correlation } \\
\text { coefficient } R\end{array}$} & \multicolumn{2}{|c|}{$\begin{array}{l}\text { Process relative } \\
\text { error } P(\%)\end{array}$} & \multicolumn{2}{|c|}{$\begin{array}{l}\text { Peak flow relative } \\
\text { error } E(\%)\end{array}$} & \multicolumn{2}{|c|}{$\begin{array}{l}\text { Water balance } \\
\text { coefficient } W\end{array}$} \\
\hline & $(1)^{*} 1$ & $(2)^{*} 2$ & $(1)^{*} 1$ & $(2)^{*} 2$ & $(1)^{*} 1$ & $(2) * 2$ & $(1)^{*} 1$ & $(2)^{*} 2$ & $(1)^{*} 1$ & $(2)^{*} 2$ \\
\hline flood1996071012 & 0.964 & 0.85 & 0.990 & 0.79 & 16.3 & 30 & 11.2 & 15.6 & 1.102 & 2.19 \\
\hline flood1998061811 & 0.862 & 0.613 & 0.930 & 0.876 & 21.4 & 194.6 & 20.8 & 39.7 & 0.963 & 1.194 \\
\hline flood2001061206 & 0.836 & 0.758 & 0.926 & 0.969 & 31.8 & 35 & 0.9 & 31.1 & 0.841 & 0.64 \\
\hline flood 2007082100 & 0.866 & 0.343 & 0.942 & 0.775 & 13.9 & 40.9 & 0.7 & 32.9 & 0.966 & 0.581 \\
\hline flood2008061114 & 0.882 & 0.74 & 0.943 & 0.883 & 20.8 & 71 & 2.5 & 31 & 0.930 & 0.36 \\
\hline flood2012040607 & 0.792 & 0.766 & 0.893 & 0.891 & 27.0 & 76.4 & 5.0 & 11.5 & 0.913 & 1.058 \\
\hline flood2012060901 & 0.912 & 0.454 & 0.958 & 0.752 & 37.0 & 74.5 & 3.2 & 1.5 & 1.072 & 1.238 \\
\hline flood2012062113 & 0.91 & 0.778 & 0.955 & 0.896 & 0.301 & 49.8 & 0.005 & 8.4 & 0.972 & 0.987 \\
\hline Average & 0.88 & 0.66 & 0.94 & 0.85 & 25 & 72 & 6 & 21 & 0.97 & 1.03 \\
\hline
\end{tabular}

*1: results simulated by model with optimized parameters, ${ }^{*} 2$ : results simulated by model with initial parameters.

performance of the Liuxihe model for catchment flood forecasting has been improved in Tiantoushui catchment. Optimizing the parameters of the Liuxihe model is necessary.

\subsection{Model validation in UMWC}

The parameters of the Liuxihe model in UMWC have been optimized by employing PSO algorithm proposed in this paper. The particle number and maximum evolution number are also set to 20 and 50 respectively; $\omega, \mathrm{C} 1$ and $\mathrm{C} 2$ 
Table 7. The evaluation index of the simulated flood events in UMWC.

\begin{tabular}{|c|c|c|c|c|c|c|c|c|c|}
\hline \multirow[b]{2}{*}{ Flood events } & \multicolumn{3}{|c|}{ Nash-Sutcliffe coefficient $C$} & \multicolumn{3}{|c|}{ Correlation coefficient $R$} & \multicolumn{3}{|c|}{ Process relative error $P$} \\
\hline & $(1)^{*} 1$ & $(2)^{*} 2$ & $(3) * 3$ & $(1)^{*} 1$ & $(2)^{*} 2$ & $(3)^{*} 3$ & $(1)^{*} 1$ & $(2)^{*} 2$ & $(3)^{*} 3$ \\
\hline flood 1980050620 & 0.906 & 0.610 & 0.810 & 0.958 & 0.831 & 0.931 & 0.168 & 0.480 & 0.288 \\
\hline flood 1980042313 & 0.892 & 0.724 & 0.824 & 0.972 & 0.768 & 0.968 & 0.282 & 0.270 & 0.307 \\
\hline flood1981041014 & 0.917 & 0.700 & 0.451 & 0.967 & 0.830 & 0.883 & 0.141 & 0.417 & 0.317 \\
\hline flood 1981040712 & 0.805 & 0.686 & 0.686 & 0.964 & 0.738 & 0.938 & 0.154 & 0.550 & 0.255 \\
\hline flood 1981041310 & 0.739 & 0.796 & 0.796 & 0.938 & 0.758 & 0.958 & 0.221 & 0.260 & 0.265 \\
\hline flood 1982051014 & 0.831 & 0.793 & 0.793 & 0.924 & 0.852 & 0.952 & 0.271 & 0.440 & 0.174 \\
\hline flood1983061513 & 0.904 & 0.810 & 0.839 & 0.954 & 0.850 & 0.925 & 0.327 & 0.530 & 0.363 \\
\hline flood 1983022720 & 0.896 & 0.750 & 0.850 & 0.974 & 0.740 & 0.934 & 0.152 & 0.220 & 0.102 \\
\hline flood 1984050310 & 0.971 & 0.800 & 0.816 & 0.989 & 0.684 & 0.980 & 0.085 & 0.380 & 0.388 \\
\hline flood 1985092216 & 0.967 & 0.840 & 0.940 & 0.986 & 0.785 & 0.978 & 0.375 & 0.480 & 0.380 \\
\hline flood 1987051422 & 0.961 & 0.853 & 0.913 & 0.986 & 0.731 & 0.973 & 0.266 & 0.241 & 0.281 \\
\hline flood 1987052012 & 0.902 & 0.727 & 0.927 & 0.951 & 0.628 & 0.968 & 0.332 & 0.362 & 0.262 \\
\hline flood 2008060902 & 0.850 & 0.756 & 0.800 & 0.923 & 0.825 & 0.820 & 0.140 & 0.414 & 0.214 \\
\hline \multirow[t]{2}{*}{ Average } & 0.888 & 0.757 & 0.8 & 0.960 & 0.771 & 0.94 & 0.248 & 0.388 & 0.28 \\
\hline & \multicolumn{3}{|c|}{ Peak flow relative error $E$} & \multicolumn{3}{|c|}{ Water balance coefficient $W$} & & & \\
\hline Flood events & $(1)^{*} 1$ & $(2)^{*} 2$ & $(3)^{*} 3$ & $(1)^{*} 1$ & $(2)^{*} 2$ & $(3)^{*} 3$ & & & \\
\hline flood 1980050620 & 0.004 & 0.230 & 0.013 & 0.913 & 0.760 & 0.796 & & & \\
\hline flood1980042313 & 0.003 & 0.270 & 0.008 & 0.867 & 0.620 & 0.792 & & & \\
\hline flood1981041014 & 0.043 & 0.180 & 0.185 & 0.973 & 0.729 & 0.729 & & & \\
\hline flood 1981040712 & 0.159 & 0.228 & 0.228 & 0.990 & 0.850 & 1.328 & & & \\
\hline flood1981041310 & 0.006 & 0.146 & 0.146 & 0.830 & 1.160 & 1.061 & & & \\
\hline flood1982051014 & 0.013 & 0.230 & 0.230 & 0.922 & 1.230 & 1.010 & & & \\
\hline flood1983061513 & 0.007 & 0.350 & 0.072 & 0.944 & 0.680 & 0.967 & & & \\
\hline flood 1983022720 & 0.018 & 0.420 & 0.078 & 1.017 & 0.650 & 1.045 & & & \\
\hline flood 1984050310 & 0.010 & 0.210 & 0.010 & 0.951 & 0.720 & 0.820 & & & \\
\hline flood1985092216 & 0.022 & 0.320 & 0.055 & 1.071 & 1.350 & 1.034 & & & \\
\hline flood 1987051422 & 0.012 & 0.280 & 0.013 & 0.925 & 1.510 & 0.892 & & & \\
\hline flood 1987052012 & 0.015 & 0.160 & 0.034 & 0.955 & 0.840 & 0.979 & & & \\
\hline flood2008060902 & 0.004 & 0.240 & 0.104 & 0.985 & 0.910 & 0.850 & & & \\
\hline Average & 0.024 & 0.251 & 0.09 & 0.949 & 0.924 & 0.95 & & & \\
\hline
\end{tabular}

are dynamically adjusted with Eqs. (4)-(6). Flood event flood 1985052618 is used to optimize the parameters.

The other 13 observed flood events of UMWC are simulated by the model with parameters optimized above. Figure 8 shows four of the simulated hydrographs. To compare, the flood events also have been simulated with the parameters optimized with a half-automated parameter adjusting method (Chen, 2009), and the results are also shown in Fig. 8. From the simulated results, it has been found that the 13 simulated hydrographs fit the observed hydrographs well. Particularly the simulated peak flow is quite good. This conclusion is the same as the results in the Tiantoushui catchment. From the results we also found that the model with initial parameter values does not simulate the observed flood event satisfactorily. The simulated results with parameters optimized with a half-automated parameter adjusting method are a big im- provement to those simulated with the initial model parameters, but the simulated results with the PSO optimized model parameters are the best among the three results.

To further analyze the model performance with parameter optimization, the five evaluation indices of the 13 simulated flood events have been calculated and are listed in Table 7 .

From Table 7 we found that the five evaluation indices have been improved by parameter optimization at different extents. For the results simulated by the model with initial parameters, the five evaluation indices - the Nash-Sutcliffe coefficient, correlation coefficient, process relative error, peak flow relative error and water balance coefficient - have average values of $0.757,0.771,38.8 \%, 25.1 \%$ and 0.924 respectively. While for the results simulated by the model with optimized parameters, the five evaluation indices have average values of $0.888,0.960,24.8 \%, 2.4 \%$ and 0.949 respec- 
tively. The peak flow relative error has been reduced from 25.1 to $2.4 \%$ after parameter optimization, which is $90.44 \%$ down and also the biggest improvement among the five evaluation indices. The average Nash-Sutcliffe coefficient has a $17.31 \%$ increase, the correlation coefficient a $24.51 \%$ increase, process relative error a $36.08 \%$ decrease and water balance coefficient a $2.71 \%$ increase. The results have a similar trend to that in the Tiantoushui catchment. This also implies that with parameter optimization by using the PSO algorithm proposed in this paper, the model performance of the Liuxihe model for catchment flood forecasting has been improved in UMWC catchment: even for a larger catchment, PSO works well for the Liuxihe model. The Liuxihe model's capability for catchment flood forecasting could be improved by parameter optimization with PSO algorithm, and the $\mathrm{Li}$ uxihe model parameter optimization is necessary.

\section{Conclusion}

In this study, based on the scalar concept, a general framework for automatic parameter optimization of the physically based distributed hydrological model is proposed, and the improved particle swarm optimization algorithm is employed for the Liuxihe model parameter optimization for catchment flood forecasting. The proposed methods have been tested in two catchments in southern China with different sizes: one small and one large. Based on the study results, the following conclusions can be drawn:

1. When employing physically based distributed hydrological model for catchment flood forecasting, uncertainty in deriving model parameters physically from the terrain properties is high. Parameter optimization is still necessary to improve the model's capability for catchment flood forecasting.

2. Capability of physically based distributed hydrological model for catchment flood forecasting, specifically the Liuxihe model studied in this paper, could be improved largely by parameter optimization with PSO algorithm, and the model performance is quite good with the optimized parameters to satisfy the requirement of real-time catchment flood forecasting.

3. Improved particle swarm optimization (PSO) algorithm proposed in this paper for physically based distributed hydrological model for catchment flood forecasting, specifically the Liuxihe model studied in this paper, has very good optimization performance. The optimized model parameters are global optimal parameters and could be used for the Liuxihe model parameter optimization for catchment flood forecasting at different size catchments.
4. The appropriate particle number of PSO algorithm used for the Liuxihe model parameter optimization for catchment flood forecasting is 20 .

5. The maximum evolution number of PSO algorithm used for the Liuxihe model parameter optimization for catchment flood forecasting is 30 .

6. The PSO algorithm has high computational efficiency and could be used in large-scale catchment flood forecasting.

Acknowledgements. This study is supported by the Special Research Grant for the Water Resources Industry (funding no. 201301070), the National Science \& Technology Pillar Program during the Twentieth Five-year Plan Period (funding no. 2012BAK10B06), the Science and Technology Program of Guangdong Province (funding no. 2013B020200007) and Water Resources Science Program of Guangdong Province (funding no. 2009-16)

Edited by: Y. Chen

\section{References}

Abbott, M. B., Bathurst, J. C., Cunge, J. A., O'Connell, P. E., and Rasmussen, J.: An Introduction to the European Hydrologic System-System Hydrologue Europeen, 'SHE', a: History and Philosophy of a Physically-based, Distributed Modelling System, J. Hydrol., 87, 45-59, 1986a.

Abbott, M. B.,Bathurst, J. C.,Cunge, J. A.,O'Connell, P. E., and Rasmussen, J.: An Introduction to the European Hydrologic System-System Hydrologue Europeen, 'SHE', b: Structure of a Physically based, distributed modeling System, J. Hydrol., 87, 61-77, 1986b.

Acharjee, P. and Goswami, S. K.: Chaotic particle swarm optimization based robust load flow, Int. J. Electr. Power Energ. Syst., 32, 141-146, 2010.

Ajami, N. K., Gupta, H., Wagener, T., and Sorooshian, S.: Calibration of a semi-distributed hydrologic model for streamflow estimation along a river system, J. Hydrol., 298, 112-135, 2004.

Ambroise, B., Beven, K., and Freer, J.: Toward a generalization of the TOPMODEL concepts: Topographic indices of hydrologic similarity, Water Resour. Res., 32, 2135-2145, 1996.

Arnold, J. G., Williams, J. R., and Srinivasan, R.: SWAT: Soil water assessment tool, US Department of Agriculture, Agricultural Research Service, Grassland, Soil and Water Research Laboratory, Temple, Texas, USA, 1994.

Arya, L. M. and Paris, J. F.: An empirical model to predict the soil moisture characteristic from particle-size distribution and bulk density data, Soil Sci. Soc. Am. J., 45, 1023-1030, 1981.

Bahareh, K. S., Mousavi, J., and Abbaspour, K. C.: Automatic calibration of HEC-HMS using single-objective and multi-objective PSO algorithms, Hydrol. Process., 27, 4028-4042, 2013.

Beven, K., Lamb, R., Quinn, P., Romanowicz, R., and Freer, J. TOPMODEL. In. Computer Models of Watershed Hydrology, edited by: Singh, V., 627-668, Baton Rouge, Florida, USA, 1995. 
Carpenter, T. M., Georgakakos, K. P., and Sperfslagea, J. A.: On the parametric and NEXRAD-radar sensitivities of a distributed hydrologic model suitable for operational use, J. Hydrol., 253, 169-193, 2001.

Chen, G., Jia, J., and Han, Q.: Study on the Strategy of Decreasing Inertia Weight in Particle Swarm Optimization Algorithm, Journal of Xi' an Jiantong University, 40, 53-56, 2006.

Chen, S., Cai, G. R., Guo, W. Z., and Chen, G. L.: Study on the Nonlinear Strategy of Acceleration Coefficient in Particle Swarm Optimization (PSO) Algorithm, Journal of Yangtze University (Nat. Sci. Edit), 1-4, 2007.

Chen, Y.: Liuxihe Model, Beijing, Science Press, 198 pp., 2009.

Chen, Y., Zhu, X., Han, J., and Cluckie, I.: CINRAD data quality control and precipitation estimation, Water Manage., 162, 95105, 2009.

Chen, Y., Ren, Q. W., Huang, F. H., Xu, H. J., and Cluckie, I.: Liuxihe Model and its modeling to river basin flood, J. Hydrol. Eng., 16, 33-50, 2011.

Chu, W., Gao, X., and Sorooshian, S.: A new evolutionary search strategy for global optimization of high-dimensional problems, Inf. Sci., 181, 4909-4927, 2011.

Chuang, L. Y., Hsiao, C. J., and Yang, C. H.: Chaotic particle swarm optimization for data clustering, Expert Syst. Appl., 38, 1455514563, 2011.

Crawford, N. H. and Linsley, R. K.: Digital simulation in hydrology, Stanford Watershed Model IV, Stanford Univ. Dep. Civ. Eng, Tech. Rep., 39, 1966.

De Smedt, F., Liu, Y. B., and Gebremeskel, S.: Hydrological modeling on a watershed scale using GIS and remote sensed land use information, edited by: Brebbia, C. A., in: Risk Analyses, WIT press, Southampton, Boston, p. 10, 2000.

Derakhshan, H. and Talebbeydokhti, N.: Rainfall disaggregation in non-recording gauge stations using space-time information system, Sci. Iran., 18, 995-1001, 2011.

Dorigo, M., Maniezzo, V., and Colorni, A.: Ant system: optimization by a colony of cooperating agents. Systems, Man, and Cybernetics, Part B: Cybernetics, IEEE Trans., 26, 29-41, 1996.

Duan, Q., Sorooshian, S., and Gupta, V. K.: Optimal use of the SCEUA global optimization method for calibrating watershed models, J. Hydrol., 158, 265-284, 1994.

Eberhart, R. C. and Shi, Y.: Tracking and optimizing dynamic systems with particle swarms, IEEE, 1, 94-100, doi:10.1109/CEC.2001.934376, 2001.

Eberhart, R. C. and Shi, Y.: Particle swarm optimization: developments, applications and resources, IEEE, 1, 81-86, doi:10.1109/CEC.2001.934374, 2001.

El-Gohary, A., Al-Ruzaiza, A. S.:Chaos and adaptive control in two prey, one predator system with nonlinear feedback, Chaos, Solitons \& Fractals, 34, 443-453, 2007.

Falorni, G., Teles, V., Vivoni, E. R., Bras, R. L., and Amaratunga, K. S.: Analysis and characterization of the vertical accuracy of digital elevation models from the Shuttle Radar Topography Mission, J. Geophys. Res. F-Earth Surf., 110, F02005, doi:10.1029/2003JF000113, 2005.

Franchini, M.: Use of a genetic algorithm combined with a local search for the automatic calibration of conceptual rainfall-runoff models, Hydrological Sciences Journal, 41, 21-39, 1996.
Freeze, R. A. and Harlan, R. L.: Blueprint for a physically-based, digitally simulated, hydrologic response model, J. Hydrol., 9, 237-258, 1969.

Fulton R. A., Breidenbach J. P. and Seo D-J., Miller, D. A.: The WSR-88D rainfall algorithm, Weather Forecast., 13, 377-395, 1998.

Goldberg, D. E.: Genetic algorithms in search, optimization and machine learning, Reading, MA, Addison-Wesley, 95-99, 1989.

Grayson, R. B., Moore, I. D., and McMahon, T. A.: Physically based hydrologic modeling: 1.A Terrain-based model for investigative purposes, Water Resour. Res., 28, 2639-2658, 1992.

Gupta, H. V., Sorooshian, S., and Yapo, P. O.: Toward improved calibration of hydrological models: multiple and noncommensurable measures of information, Water Resour. Res., 34, 751-763, 1998.

Hendrickson, J. D., Sorooshian, S., and Brazil, L. E.: Comparison of Newton-type and direct search algorithms for calibration of conceptual rainfall-runoff models, Water Resour. Res., 24, 691700, 1988.

Holland, J. H.: Adaptation in natural and artificial systems:An introductory analysis with applications to biology, control, and artificial intelligence, Cambridge, MA, University of Michigan Press, ISBN:0262082136, 1992.

Hooke, R. and Jeeves, T. A.: "Direct Search" Solution of Numerical and Statistical Problems, JACM, 8, 212-229, 1961.

Ibbitt, R. P. and O'Donnell, T.: Designing conceptual catchment models for automatic fitting methods, IAHS Publication, 101, 462-475, 1971.

Immerzeel, W. W. and Droogers, P.: Calibration of a distributed hydrological model based on satellite evapotranspiration, J. Hydrol., 349, 411-424, 2008.

Jasper, A.. Vrugt, H. V., and Gupta, W. B.:A Shuffled Complex Evolution Metropolis algorithm for optimization and uncertainty assessment of hydrologic model parameters, Water Resour. Res., 39, 1201, doi:10.1029/2002WR001642, 2003.

Jeraldin, A. D. and Anitta, T.: PSO tuned PID-based Model Reference Adaptive Controller for coupled tank system, Applied Mechanics and Materials Trans Tech Publications, Switzerland, doi:10.4028/www.scientific.net/AMM.626.167, 626 pp., 167171, 2014.

Jia, Y., Ni, G., and Kawahara, Y.: Development of WEP model and its application to an urban watershed, Hydrol. Process., 15, 2175-2194, 2001.

Julien, P. Y., Saghafian, B., and Ogden, F. L.: Raster-Based Hydrologic Modeling of spatially-Varied Surface Runoff, Water Resour. Bulletin, 31, 523-536, 1995.

Kavvas, M., Chen, Z., Dogrul, C., Yoon, J., Ohara, N., Liang, L., Aksoy, H., Anderson, M., Yoshitani, J., Fukami, K., and Matsuura, T.: Watershed Environmental Hydrology (WEHY) Model Based on Upscaled Conservation Equations: Hydrologic Module, J. Hydrol. Eng., 9, 450-464, doi:10.1061/(ASCE)10840699, 2004.

Kavvas, M., Yoon, J., Chen, Z., Liang, L., Dogrul, E., Ohara, N., Aksoy, H., Anderson, M., Reuter, J., and Hackley, S.: Watershed Environmental Hydrology Model: Environmental Module and Its Application to a California Watershed, J. Hydrol. Eng., 11, 261272, doi:10.1061/(ASCE)1084-0699, 2006. 
Kennedy, J. and Eberhart, R.: Particle swarm optimization: Proceedings, IEEE International Conference on Neural Networks, Picataway NJ, IEEE Service Center, 1942-1948, 1995.

Kirkpatrick, S., Gelatt, C. D., and Vecchi, M.: Optimization by simulated annealing, Science, 220, 671-680, 1983.

Kouwen, N.: WATFLOOD: A Micro-Computer based Flood Forecasting System based on Real-Time Weather Radar, Canad. Water Resour. J., 13, 62-77, 1988.

Laloy, E., Fasbender, D., and Bielders, C. L.: Parameter optimization and uncertainty analysis for plot-scale continuous modeling of runoff using a formal Bayesian approach, J. Hydrol., 380, 8293, 2010.

Leila, O. , Miguel, A., and Mariño, A. A.: Multi-reservoir Operation Rules: Multi-swarm PSO-based Optimization Approach, Water Resour. Manage., 26, 407-427, 2012.

Leta O. T, Nossent J., Velez C., Shrestha N. K., Griensven, A., and Bauwens W.: Assessment of the different sources of uncertainty in a SWAT model of the River Senne (Belgium), Environ. Model. Softw., 68, 129-146, 2015.

Li, X., Chun, C., Xin, W., and Jian, L.: Study on Fuzzy Multiobjective SCE-UA Optimization Method for Rainfall-Runoff Models, Eng. Sci., 3, 52-57, 2007.

Liang, X., Lettenmaier, D. P., Wood, E. F., and Burges, S. J.: A simple hydrologically based model of land surface water and energy fluxes for general circulation models, J. Geophys. Res, 99, 14415-14428, 1994.

Loveland, T. R., Merchant, J. W., Ohlen, D. O., and Brown, J. F.: Development of a Land Cover Characteristics Data Base for the Conterminous U.S., Photogram. Eng. Remote Sens., 57, 14531463, 1991

Loveland, T. R., Reed, B. C., Brown, J. F., Ohlen, D. O., Zhu, J., Yang, L., and Merchant, J. W.: Development of a Global Land Cover Characteristics Database and IGBP DISCover from 1-km AVHRR Data, Int. J. Remote Sens., 21, 1303-1330, 2000.

Madsen, H.: Parameter estimation in distributed hydrological catchment modelling using automatic calibration with multiple objectives, Adv. Water Resour., 26, 205-216, 2003.

Masri, S. F., Bekey, G. A., and Safford, F. B.: A global optimization algorithm using adaptive random search, Appl. Math. Comput., 7, 353-375, 1980.

Nash, J. E. and Sutcliffe, J. V.: River flow forecasting through conceptual models part - A discussion of principles, J. Hydrol., 10, 282-290, 1970.

Nelder, J. A. and Mead, R.: A simple method for function minimization, Comp. Journey, 7, 308-313, 1965.

O'Connell, P. E, Nash, J. E., and Farrell, J. P.: River flow forecasting through conceptual models part - The Brosna catchment at Ferbane, J. Hydrol., 10, 317-329, 1970.

Pokhrel, P., Gupta, H. V., and Wagener, T.: A spatial regularization approach to parameter estimation for a distributed watershed model, Water Resour. Res., 44, W12419, doi:10.1029/2007WR006615, 2008.

Pokhrel, P., Yilmaz, K. K., Gupta, H. V.: Multiple-criteria calibration of a distributed watershed model using spatial regularization and response signatures, J. Hydrol., 418-419, 49-60, 2012.

Poli, R.: Analysis of the publications on the applications of particle swarm optimisation. Journal of Artificial Evolution and Applications, 1-10, 2008.
Poli, R., Kennedy, J., and Blackwell, T.: Particle swarm optimization. Swarm Intelligence, 1, 33-57, 2007.

Ratnaweera, A., Halgamuge, S. K., and Watson, H. C.: Selforganizing hierarchical particle swarm optimizer with timevarying acceleration coefficients, Evolutionary Computation, IEEE Trans., 8, 240-255, 2004.

Reed, S., Koren, V., Smith, M., Zhang, Z., Moreda, F., and Seo, D.J.: DMIP participants: Overall distributed model intercomparison project results, J. Hydrol., 298, 27-60, 2004.

Refsgaard, J. C. and Storm, B.: Construction, calibration and validation of hydrological models, in: Distributed Hydrological Modelling, edited by: Abbott, M. B. and Refsgaard, J. C., Kluwer Academic, Springer Netherlands, 41-54, 1996.

Refsgaard, J. C.: Parameterisation, calibration and validation of distributed hydrological models, J. Hydrol., 198, 69-97, 1997.

Resffa, F., O' Castillo., Fevrier, V., and Leticia, C.: Design of Optimal Membership Functions for Fuzzy Controllers of the Water Tank and Inverted Pendulum with PSO Variants, IFSA World Congress and NAFIPS Annual Meeting (IFSA/NAFIPS), 10681073, 2013.

Rosenbrock, H. H.: An automatic method for finding the greatest or least value of a function, Comp. Journey, 3, 175-184, 1960.

Richard, A., Annie, P., Pascal, C., and François, B.: Comparison of Stochastic Optimization Algorithms in Hydrological Model Calibration, American Society of Civil Engineers, doi:10.1061/(ASCE)HE.1943-5584.0000938, 1374-1384, 2014.

Shafii, M. and De Smedt, F.: Multi-objective calibration of a distributed hydrological model (WetSpa) using a genetic algorithm, Hydrol. Earth Syst. Sci., 13, 2137-2149, doi:10.5194/hess-132137-2009, 2009.

Sharma, A. Tiwari, K. N.: A comparative appraisal of hydrological behavior of SRTM DEM at catchment level, J. Hydrol., 519, 1394-1404, 2014.

Sherman, L. K.: Streamflow from Rainfall by the Unit-Graph Method, Eng. News-Rec., 108, 501-505 1932.

Shi, Y. and Eberhart, R. C.: A modified particle swarm optimizer, IEEE, 69-73, doi:10.1109/ICEC.1998.699146, 1998.

Shi, Y. and Eberhart, R. C.: Fuzzy adaptive particle swarm optimization, IEEE, 1, 101-106, doi:10.1109/CEC.2001.934377, 2001.

Shu, X. J., Chen, Y. B., Huang, F. H., and Zhou, H. L.: Application of PEST in the Parameter Calibration of Wetspa Distributed Hydrological Model, J. China Hydrol., 29, 45-49, 2009.

Singh, V. P.: Computer Models of Watershed Hydrology, Water Resources Publications, Colorado, 1130, ISBN:0-918334-91-8, 1995.

Smith, M. B., Seo, D.-J., Koren, V. I., Reed, S., Zhang, Z., Duan, Q.-Y., Cong, S., Moreda, F., and Anderson, R.: The distributed model intercomparison project (DMIP): motivation and experiment design, J. Hydrol., 298, 4-26, 2004.

Song, S. L., Kong, L., Gan, Y., and Rijian, S. B.: Hybrid particle swarm cooperative optimization algorithm and its application to MBC in alumina production, Prog. Natural Sci., 18, 1423-1428, 2008.

Sorooshian, S., Gupta, V. K., and Fulton, J. L.: Evaluaion of maximum likehood parameter estimation techniques for conceptual rainfall-runoff models:Influence of calibration data variability and length on model credibility, Water Resour. Res., 19, 251$259,1983$. 
Sorooshian, S., Gupta, V. K.:Model calibration. In: Singh VP, editor. Computer models of watershed hydrology, Colorado, Water Resources Publications, 23-68, 1995.

Storn, R. and Price, K.: Differential evolution e a simple and efficient heuristic for global optimization over continuous spaces, J. Global Opt., 11, 341-359, 1997.

Tang, Y., Reed, P., and Wagener, T.: How effective and efficient are multiobjective evolutionary algorithms at hydrologic model calibration?, Hydrol. Earth Syst. Sci., 10, 289-307, doi:10.5194/hess-10-289-2006, 2006.

Vieux, B. E.: Distributed Hydrologic Modeling Using GIS, second ed. Water Science Technology Series, vol. 48. ISBN:1-40202459-2, Kluwer Academic Publishers, Norwell, Massachusetts, p. $289,2004$.

Vieux, B. E. and Moreda, F. G.: Ordered physics-based parameter adjustment of a distributed model, in: Advances in Calibration of Watershed Models, edited by: Duan, Q., Sorooshian, S., Gupta, H. V., Rousseau, A. N., Turcotte, R., Water Science and Application Series, vol. 6. American Geophysical Union, 267281, ISBN:0-87590-335-X (Chapter 20), 2003.

Vieux, B. E. and Vieux, J. E.: Vflo ${ }^{\mathrm{TM}}$ : A Real-time Distributed Hydrologic Model[A], in: Proceedings of the 2nd Federal Interagency Hydrologic Modeling Conference, 28 July-1 August, Las Vegas, Nevada, Abstract and paper on CD-ROM, 2002.
Vieux, B. E., Cui, Z., and Gaur, A.: Evaluation of a physics-based distributed hydrologic model for flood forecasting, J. Hydrol., 298, 155-177, 2004.

Wigmosta, M. S., Vai, L. W., and Lettenmaier, D. P.: A Distributed Hydrology-Vegetation Model for Complex Terrain, Water Resour. Res., 30, 1665-1669, 1994.

Vrugt, J. and Robinson, B.: Improved evolutionary optimization from genetically adaptive multimethod search, P. Natl. Acad. Sci. USA, 104, 708-711, 2007.

Wang, Z., Batelaan, O., and De Smedt, F.: A distributed model for water and energy transfer between soil, plants and atmosphere (WetSpa), J. Phys. Chem. Earth, 21, 189-193, 1997.

Yang, D., Herath, S., and Musiake, K.: Development of a geomorphologic properties extracted from DEMs for hydrologic modeling, Ann. J. Hydr. Eng., JSCE, 47, 49-65, 1997.

Zambrano-Bigiarini, M. and Rojas, R.: A model-independent Particle Swarm Optimisation software for model calibration, Environ. Model. Softw., 43, 5-25, 2013.

Zhang, X., Srinivasan, R., and Liew, M. V.: Multi-site calibration of the SWAT model for hydrologic modeling, Transactions of the ASABE, 51, 2039-2049, 2008.

Zhao, R. J.: Flood Forecasting Method for Humid Regions of China. East China College of Hydraulic Engineering, Nanjing, China, 1977. 